\title{
Synthesis and Characterization of New MAX Phase Alloys
}

Aurelija Mockutè

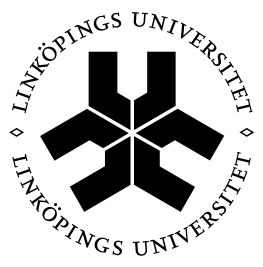

\section{Linköping University} INSTITUTE OF TECHNOLOGY

Thin Film Physics Division

Department of Physics, Chemistry and Biology (IFM)

Linköping University

SE-581 83 Linköping, Sweden 
The cover image is based on a cross-sectional TEM micrograph of a high current pulsed cathodic arc deposited $\left(\mathrm{Cr}_{0.8} \mathrm{Mn}_{0.2}\right)_{2} \mathrm{AlC}$ thin film (20 nm thickness), revealing its island-like nature.

(C) Aurelija Mockutè

ISBN: 978-91-7519-407-3

ISSN 0345-7524

Printed by LiU-Tryck

Linköping, Sweden, 2014 


\section{Abstract}

This Thesis explores synthesis and characterization of new MAX phase alloys $(M=$ early transition metal, $A=\mathrm{A}$-group element, and $X=\mathrm{C}$ or $\mathrm{N}$ ), based on incorporation of $M$ and $X$ elements previously not considered. My primary focus is on $M=\mathrm{Mn}$ for attaining magnetic properties, and on $X=\mathrm{O}$ for potential tuning of the transport properties. A recent theoretical study predicted $\left(\mathrm{Cr}_{1-\mathrm{x}} \mathrm{Mn}_{\mathrm{x}}\right)_{2} \mathrm{AlC} \mathrm{MAX}$ phase to be a stable magnetic nanolaminate. I aimed at realizing this material and through a combinatorial approach based on magnetron sputtering from elemental targets, the first experimental evidence of Mn incorporation $(x=0.16)$ in a MAX phase is presented. The corresponding MAX phase was also synthesized using cathodic arc film deposition $(x=0.20)$ and bulk synthesis methods $(x=0.06)$. The primary characterization techniques were X-ray diffraction and high-resolution (scanning) transmission electron microscopy in combination with energy dispersive X-ray spectroscopy and/or electron energy loss spectroscopy, to obtain a precise local quantification of the MAX phase composition and to perform lattice resolved imaging. For epitaxial film growth of $\left(\mathrm{Cr}_{1-\mathrm{x}} \mathrm{Mn}_{\mathrm{x}}\right)_{2} \mathrm{AlC}$, evidence is presented for the formation of $\left(\mathrm{Cr}_{1-\mathrm{y}} \mathrm{Mn}_{\mathrm{y}}\right)_{5} \mathrm{Al}_{8}$, exhibiting a bcc structure with an interplanar spacing matching exactly half a unit cell of the hexagonal MAX phase. Consequently, routinely performed X-ray diffraction symmetric $\theta-2 \theta$ measurements result in peak positions that are identical for the two phases. As $\left(\mathrm{Cr}_{1-\mathrm{y}} \mathrm{Mn}_{\mathrm{y}}\right)_{5} \mathrm{Al}_{8}$ is shown to display a magnetic response, its presence needs to be taken into consideration when evaluating the magnetic properties of the MAX phase. Methods to distinguish between $(\mathrm{Cr}, \mathrm{Mn})_{5} \mathrm{Al}_{8}$ and $(\mathrm{Cr}, \mathrm{Mn})_{2} \mathrm{AlC}$ are also suggested. As different $A$-element in the MAX phase is theoretically predicted to influence phase stability, attainable level of $\mathrm{Mn}$ incorporation, as well as magnetic properties, thin films of $\left(\mathrm{Cr}_{0.75} \mathrm{Mn}_{0.25}\right)_{2} \mathrm{GeC}$ and bulk $\left(\mathrm{Cr}_{0.7} \mathrm{Mn}_{0.3}\right)_{2} \mathrm{GaC}$ have also been synthesized. Vibrating sample magnetometry measurements display a magnetic response for all these materials, identifying $(\mathrm{Cr}, \mathrm{Mn})_{2} \mathrm{AlC},(\mathrm{Cr}, \mathrm{Mn})_{2} \mathrm{GeC}$, and $(\mathrm{Cr}, \mathrm{Mn})_{2} \mathrm{GaC}$ as 
the first magnetic MAX phases. The results presented in this Thesis show that $A=\mathrm{Al}$ displays the highest magnetic transition temperature (well above room temperature) and $A=\mathrm{Ga}$ allows the highest $\mathrm{Mn}$ content. The attainable $\mathrm{O}$ incorporation in $\mathrm{Ti}_{2} \mathrm{Al}\left(\mathrm{C}_{1-\mathrm{x}} \mathrm{O}_{\mathrm{x}}\right)$ MAX phase was explored by arc deposition of $\mathrm{Ti}_{2} \mathrm{AlC}_{1-\mathrm{y}}$ thin films under high vacuum conditions, and solidstate reactions following deposition of understoichiometric $\mathrm{TiC}_{\mathrm{z}}$ on $\mathrm{Al}_{2} \mathrm{O}_{3} \cdot \mathrm{Ti}_{2} \mathrm{Al}\left(\mathrm{C}_{1-\mathrm{x}} \mathrm{O}_{\mathrm{x}}\right)$ thin films with up to 13 at.\% $\mathrm{O}(x=0.52)$ were synthesized, and $\mathrm{O}$ was shown to occupy the $\mathrm{C}$ lattice site. The obtained $\mathrm{O}$ concentration is enough to allow future experimental investigations of the previously suggested (from theory) substantial change in anisotropic electronic properties with increasing $\mathrm{O}$ content. The experimental results obtained in this Thesis expand the MAX phase definition and the materials characteristics into new research areas, towards further fundamental understanding and functionalization. 


\section{Populärvetenskaplig}

\section{sammanfattning}

Materialvetenskap inkluderar forskning på material, dess syntes, struktur och sammansättning samt resulterande egenskaper, med fokus på att utveckla nya material skräddarsydda för specifika ändamål.

En viktig del inom materialvetenskapen är forskning på tunna filmer, d.v.s. lager av material med tjocklek från ett atomlager till några mikrometer. Egenskaperna hos en yta, till exempel friktion, slitmotstånd, ledningsförmåga, eller utseende, kan förbättras genom att applicera en lämplig tunnfilm.

Den här avhandlingen handlar om en grupp material som kallas MAX-faser. $M$ står för en övergångsmetall (t.ex. Ti, $\mathrm{Cr}, \mathrm{Nb}, \mathrm{Sc}$ ), $A$ för ett element från grupp $\mathrm{A}$ i det periodiska systemet (t.ex. $\mathrm{Al}, \mathrm{Si}, \mathrm{Ge}, \mathrm{Ga}$ ), och $X$ står för $\mathrm{C}$ eller $\mathrm{N}$. Atomer av tre sådana olika element staplas $\mathrm{i}$ en struktur bestående av rena atomlager, t.ex. $M-X-M-A-M-X-M-A . \mathrm{Ti}_{2} \mathrm{AlC}, \mathrm{Cr}_{2} \mathrm{AlC}$, $\mathrm{Ti}_{3} \mathrm{SiC}_{2}$ och $\mathrm{Ti}_{4} \mathrm{AlN}_{3}$ är några exempel av mer än 60 hittills upptäckta MAX-faser. Det extra spännande med MAX-faser är att de kombinerar metalliska och keramiska egenskaper. De leder alltså ström och värme, men tål samtidigt höga temperaturer och de står emot oxidation. Dock, oavsett hur bra något är, kan det alltid göras ännu bättre.

Nyligen har det publicerats teoretiska beräkningar som visar att tillsatser av nya atomslag i MAX-faser kan leda till helt nya egenskaper. Till exempel skulle syre (O) i $\mathrm{Ti}_{2} \mathrm{AlC}$ kunna styra ledningsförmågan, och mangan $(\mathrm{Mn})$ i $\mathrm{Cr}_{2} \mathrm{AlC}$ skulle kunna resultera i magnetiska 
egenskaper. Det sistnämnda är särskilt intressant, då MAX-fasernas lagrade struktur gör att de skulle kunna passa för magnetisk datalagring och dataöverföring på ett bättre sätt än den teknologi som används i stor skala idag.

I min forskning har jag utgått från ovan nämnda beräkningar och undersökt hur mycket $\mathrm{O}$ och Mn det är möjligt att få in i tunna filmer av $\mathrm{Ti}_{2} \mathrm{AlC}$ respektive $\mathrm{Cr}_{2} \mathrm{AlC}$, samt vilken effekt de nya elementen har på materialets struktur och egenskaper. Jag har lyckats byta ut hälften av kolatomerna mot syre $\mathrm{i} \mathrm{Ti}_{2} \mathrm{AlC}$, vilket enligt teoretiska beräkningar är det högsta nåbara och dessutom tillräckligt för att möjliggöra framtida studier av hur ledningsförmågan förändras. Med olika förbättrade framställningsprocesser har jag också lyckats inkorporera Mn i tunna filmer av $\mathrm{Cr}_{2} \mathrm{AlC}$ och i de relaterade MAX-faserna $\mathrm{Cr}_{2} \mathrm{GeC}$ och $\mathrm{Cr}_{2} \mathrm{GaC}$, samt även undersökt möjligheten att använda $\mathrm{Mn}$ i bulksyntes. Det visar sig att minst en fjärdedel av $\mathrm{Cr}$ kan bytas

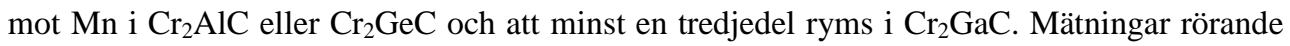
magnetiska egenskaper hos dessa material bevisar att alla tre är magnetiska, d.v.s. helt nya slags material. 


\section{Preface}

This Thesis is the result of my Ph.D. studies conducted from November 2008 to March 2014 in the Thin Film Physics Division at the Department of Physics, Chemistry and Biology (IFM) at Linköping University. The work is a continuation of my Licentiate Thesis "Thin Film Synthesis and Characterization of New MAX Phase Alloys" (Licentiate Thesis No. 1538, Linköping Studies in Science and Technology, 2012). The research has been performed in cooperation with RWTH-Aachen (Germany), University of Iceland (Iceland), Drexel University (USA), and Uppsala University. Financial support has been provided by the Swedish Research Council (VR). 



\section{Acknowledgments}

A Ph.D. is not a lonely journey. I am fortunate that during these years I have been surrounded by the best companions one can imagine. It has been an honor and a pleasure to work with such professional and inspiring people towards the same goal. I have learned a lot, far beyond to what is described in words in this Thesis.

I would like to express my sincere gratitude to -

Johanna Rosén, my supervisor

Lars Hultman, my co-supervisor

All of the co-authors, especially -

Árni Sigurður Ingason

Andrejs Petruhins

Martin Dahlqvist

Per Persson

Ju Lu

Jens Emmerlich and Jochen Schneider at RWTH Aachen University

Michel Barsoum at Drexel University

And last, but not least -

My family and friends 



\section{Included papers}

\section{Paper I}

Synthesis and ab initio calculations of nanolaminated $(\mathrm{Cr}, \mathrm{Mn})_{2} \mathrm{AlC}$ compounds

A. Mockute, M. Dahlqvist, J. Emmerlich, L. Hultman, J.M. Schneider, P.O.Å. Persson, and J. Rosen

Physical Review B 87: 094113 (2013).

\section{Paper II}

Magnetic self-organized atomic laminate from first principles and thin film synthesis

A.S. Ingason, A. Mockute, M. Dahlqvist, F. Magnus, S. Olafsson, U.B. Arnalds, B. Alling, I.A. Abrikosov, B. Hjorvarsson, P.O.Å. Persson, and J. Rosen Physical Review Letters 110: 195502 (2013).

\section{Paper III}

Synthesis and characterization of arc deposited magnetic $(\mathrm{Cr}, \mathrm{Mn})_{2} \mathrm{AlC} \mathrm{MAX}$ phase films A. Mockute, P.O.Å. Persson, F. Magnus, A.S. Ingason, S. Olafsson, L. Hultman, and J. Rosen

Submitted for publication. 


\section{Paper IV}

Structural and magnetic properties of $\left(\mathrm{Cr}_{1-x} M n_{x}\right)_{5} A l_{8}$ solid solution and structural relation to hexagonal nanolaminates

A. Mockute, P.O.Å. Persson, J. Lu, A.S. Ingason, F. Magnus, S. Olafsson, L. Hultman, and J. Rosen

Submitted for publication.

\section{Paper V}

Solid solubility and magnetism upon Mn incorporation in bulk $\mathrm{Cr}_{2} \mathrm{AlC}$ and $\mathrm{Cr}_{2} \mathrm{GaC} \mathrm{MAX}$ phases

A. Mockute, J. Lu, E.J. Moon, M. Yan, B. Anasori, S.J. May, M.W. Barsoum, and J. Rosen,

Submitted for publication.

\section{Paper VI}

Oxygen incorporation in $\mathrm{Ti}_{2} \mathrm{AlC}$ thin films studied by electron energy loss spectroscopy and ab initio calculations

A. Mockute, M. Dahlqvist, L. Hultman, P.O.Å. Persson, and J. Rosen

Journal of Materials Science 48(10): 3686-3691 (2013). 


\section{My contribution to the}

\section{included papers}

\section{Paper I}

I planned and performed all depositions, XRD characterization, participated in the analysis of TEM and EDX results, and was responsible for writing the paper.

\section{Paper II}

I was involved in project planning, performed some of the depositions and XRD characterization, and contributed to writing of the paper.

\section{Paper III}

I planned and performed all depositions, XRD and SEM characterization, participated in analysis of TEM, EDX, and VSM results, and was responsible for writing the paper.

\section{Paper IV}

I planned and performed all depositions, XRD characterization, participated in the analysis of TEM, EDX, and VSM results, and was responsible for writing the paper. 


\section{Paper V}

I planned and performed all synthesis, XRD, SEM and EDX characterization, participated in analysis of TEM, EDX, and VSM results, and was responsible for writing the paper.

\section{Paper VI}

I performed some of the depositions, all XRD characterization, and was responsible for writing the paper. 


\section{Related papers}

\section{Paper VII}

Phase stability of $\mathrm{Cr}_{n+1} \mathrm{GaC}_{n} \mathrm{MAX}$ phases from first principles and $\mathrm{Cr}_{2} \mathrm{GaC}$ thin-film synthesis using magnetron sputtering from elemental targets

A. Petruhins, A.S. Ingason, M. Dahlqvist, A. Mockute, M. Junaid, J. Birch, J. Lu, L. Hultman, P.O.Å. Persson, and J. Rosen

Physica Status Solidi RRL 7(11): 971-974 (2013).

\section{Paper VIII}

A nanolaminated magnetic phase: $\mathrm{Mn}_{2} \mathrm{GaC}$

A.S. Ingason, A. Petruhins, M. Dahlqvist, F. Magnus, A. Mockute, B. Alling, L. Hultman, I.A. Abrikosov, P.O.Å. Persson, and J. Rosen

Materials Research Letters 2(2): 89-93 (2014). 



\section{Table of contents}

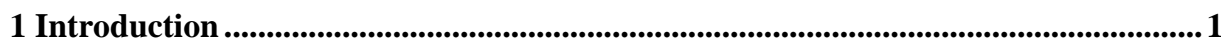

1.1 Materials science

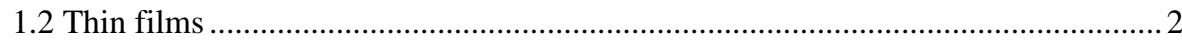

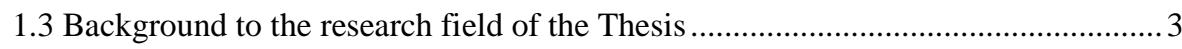

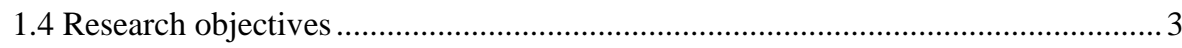

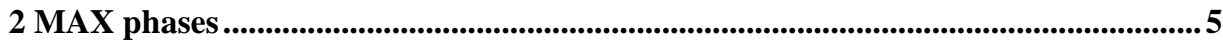

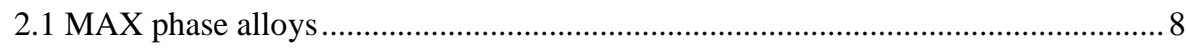

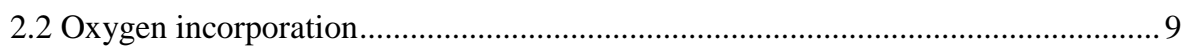

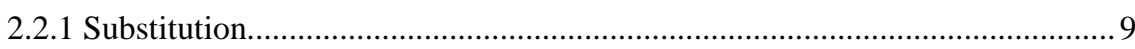

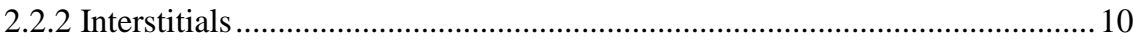

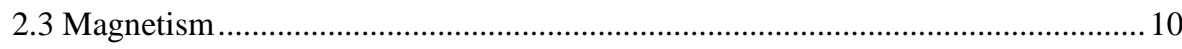

3 Materials synthesis ........................................................................................................ 15

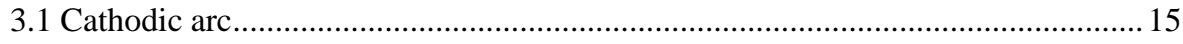

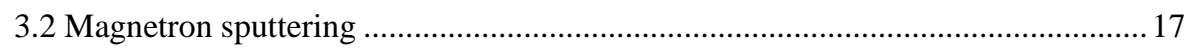

3.3 Plasma-surface interaction during thin film synthesis .........................................2 20

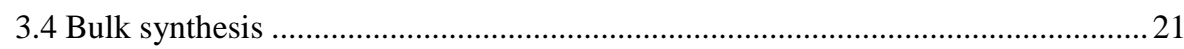

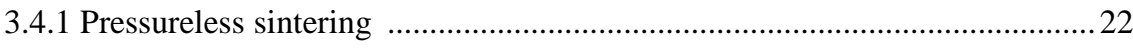

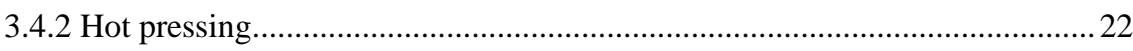

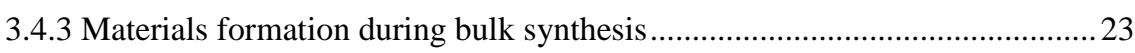

3.5 Advantages and limitations of bulk and thin film synthesis ..................................2 24 
4 Materials characterization techniques ..........................................................................22

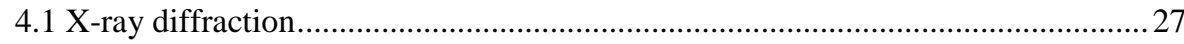

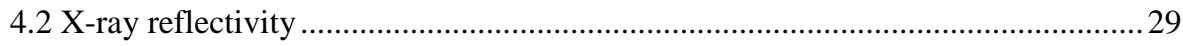

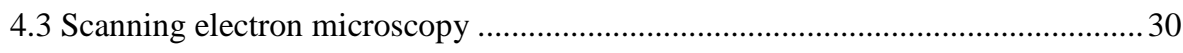

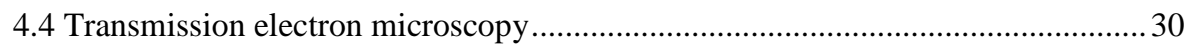

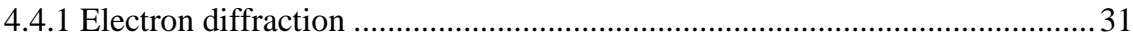

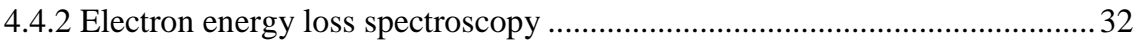

4.4.3 Energy dispersive X-ray spectroscopy ….................................................. 32

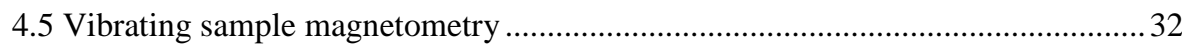

5 MAX phase synthesis and characterization...................................................................35

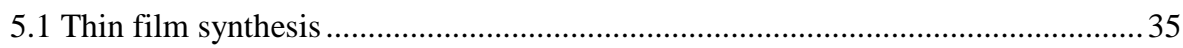

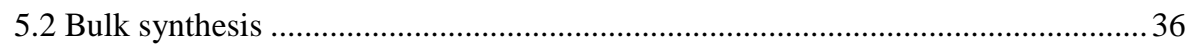

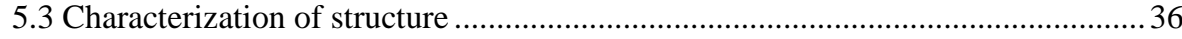

5.4 Characterization of composition ................................................................. 40

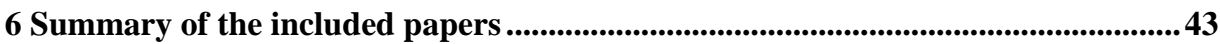

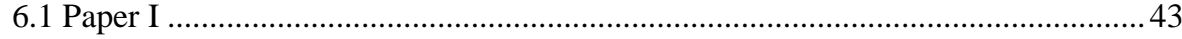

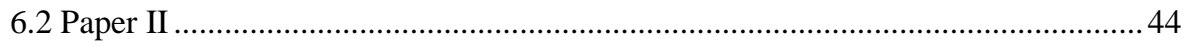

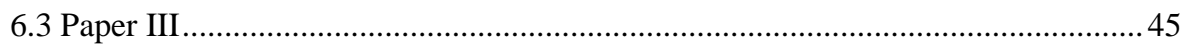

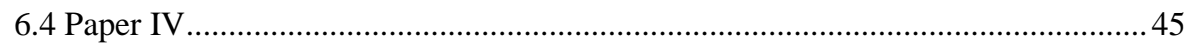

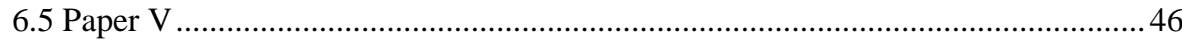

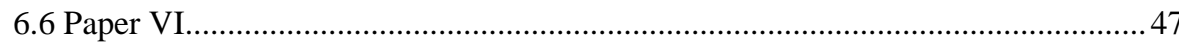

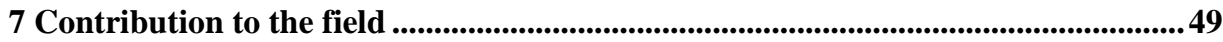

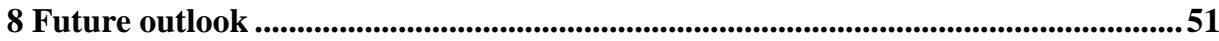

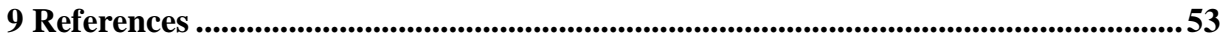




\section{Introduction}

\subsection{Materials science}

Materials science is an interdisciplinary field involving the study of properties of materials and how those are determined by composition and (micro-)structure. Various methods are employed to produce materials with desired properties, which in turn result in optimal performance for specific purposes. The materials science paradigm is presented in Figure 1.1.

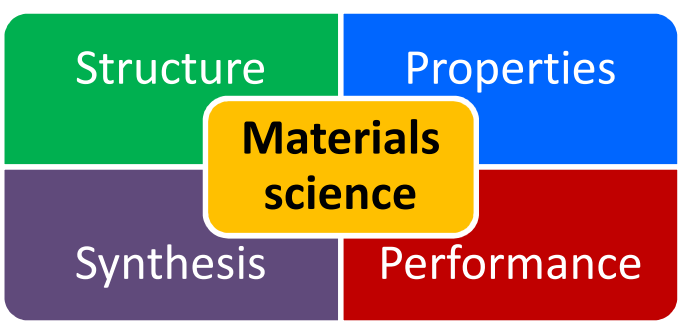

Figure 1.1. Materials science joins together studies of materials synthesis, structure, properties, and performance.

Materials science is a broad research field in the sense that it covers all the way from initial studies of new materials to their final performance. A wide range of materials is studied, including metals, ceramics, glasses, polymers, and various composites thereof. The materials may be composed of single elements or involve a considerable number of different atomic species arranged in complex crystal structures. The size scale ranges from one dimensional quantum dots and advanced nanostructures to polycrystalline bulk material. 
Almost everything surrounding us in our modern society is a result of discoveries and developments in materials science. Once started off as small test samples in laboratories, it eventually scales up to industrial-size fabrication, resulting in products that soon find a place in our everyday life, such as energy saving light bulbs, computers, non-stick cookware, remote controls, gas sensors, medical implants, etc.

Materials largely affect the way we live. Still, the fast pace of the modern life and the issues it brings, such as the urgent necessity to use natural resources more effectively and to employ new energy sources, challenges the materials science and affects its direction. New materials with better performance are constantly on demand. For example, lighter and more heatresistant material for jet engines would save millions of barrels of fuel per year - and would also have a staggering impact from the economics perspective.

\subsection{Thin films}

Thin film physics is a branch of materials science investigating layers of materials with thickness ranging from one monolayer up to several micrometers. Over the last decades, the field of thin film physics has expanded both as research area as well as in the number of applications.

The most straightforward application of thin films is covering a bulk material with a suitable coating. Interaction with the environment occurs at the surface, and therefore a proper surface modification can lead to improved materials performance, e.g., reduced friction, increased damage resistance, or appealing appearance, etc., while allowing easier manufacturing and lower cost of the bulk material underneath.

More advanced applications include stacking different materials with different thicknesses into multilayer structures, where the final performance is determined not by a homogeneous film, but rather a combination of films, also including effects from the interfaces in between. Examples of multilayer devices are, e.g., Bragg mirrors used in optoelectronics and hard disk drives for magnetic recording, the latter based on giant magnetoresistance effect in ferromagnetic/non-magnetic layer stackings. 


\subsection{Background to the research field of the Thesis}

The focus of this Thesis is thin films of materials belonging to a group of $M_{n+l} A X_{n}$ (MAX) phases, where $M$ denotes an early transition metal, $A-$ an A-group element, and $X-\mathrm{C}$ or $\mathrm{N}$. The first members in the MAX phase family were synthesized already in 1960's [1], but gained the research attention they deserve only in 1990's after the discovery of extremely high thermal shock and mechanical damage tolerance, as well as a combination of metallic and ceramic properties in $\mathrm{Ti}_{3} \mathrm{SiC}_{2}[2]$.

Extensive research on MAX phase thin films started in 2002 by synthesis of $\mathrm{Ti}_{3} \mathrm{SiC}_{2}$ [3], and has primarily been directed towards obtaining phase pure epitaxial thin films with high crystal quality for subsequent characterization. Potential applications of MAX phase thin films include, e.g., wear resistant and self-lubricant coatings, and electrical contacts.

During the past two decades the MAX phase research field has advanced enormously in terms of materials synthesized and properties investigated, e.g., oxidation resistance, mechanical properties, and transport properties. Currently, the research efforts are directed towards, for example, 2D structures, such as graphene-like exfoliated MAX phase sheets (MXenes) [4-6], MAX phase nanotubes [7], manufacturing of freestanding structures [8], as well as understanding their optical [9, 10], anisotropic [11-13], and magnetic [14-19] properties.

\subsection{Research objectives}

The objectives within this Thesis is to investigate the possibility to add novel properties to MAX phases as well as to tune the already existing ones through alloying known phases with hitherto unexplored $M$ and $X$ elements. The focus is directed towards providing MAX phases with magnetic properties by substituting $\mathrm{Cr}$ with $\mathrm{Mn}$ in $\mathrm{Cr}_{2} \mathrm{AlC}, \mathrm{Cr}_{2} \mathrm{GeC}$, and $\mathrm{Cr}_{2} \mathrm{GaC}$ systems, following the most recent theoretical predictions. Substitution of $\mathrm{C}$ with $\mathrm{O}$ in $\mathrm{Ti}_{2} \mathrm{AlC}$ is also investigated, in an attempt to cover the range of $\mathrm{O}$ concentrations for which change in the conductivity along c-axis is expected based on previously reported theoretical calculations. 



\section{MAX phases}

MAX phases are formed by elements marked in the periodic table in Figure 2.1, where $M$ elements are highlighted in red, $A$ in blue, and $X$ in black, corresponding to early transition metals, A-group elements, and carbon/nitrogen, respectively. More than 60 MAX phases have been synthesized to date, most of them in polycrystalline bulk form. Systematic investigations of MAX phase thin films began in 2002 with deposition of $\mathrm{Ti}_{3} \mathrm{SiC}_{2}$ [3] which has accelerated the expansion of the research field even further [20].

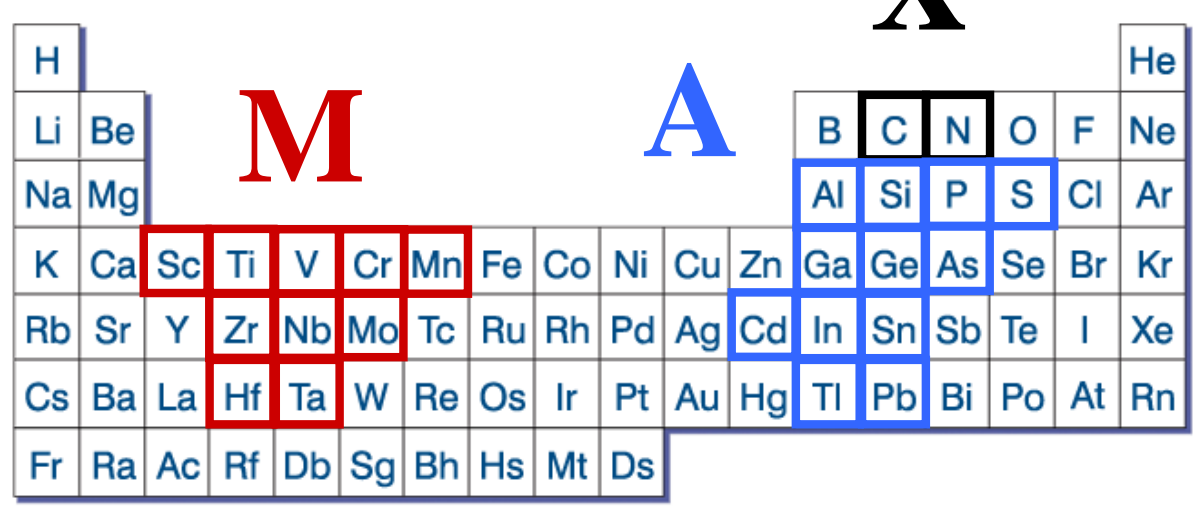

Figure 2.1. Periodic table illustrating elements forming all MAX phases known to date.

MAX phases acquire a hexagonal crystal structure (space group $\mathrm{P} 6_{3} / \mathrm{mmc}$ ), which can be described as $\mathrm{M}_{6} \mathrm{X}$ edge sharing octahedra interleaved by layers of $A$ element. The general composition can be written as $\mathrm{M}_{\mathrm{n}+1} \mathrm{AX}_{\mathrm{n}}$, where $n$ is an integer number. Different 
stoichiometries $\left(\mathrm{M}_{2} \mathrm{AX}, \mathrm{M}_{3} \mathrm{AX}\right.$, etc.) are often referred to as 211,312 , etc. The corresponding unit cells together with the resulting nanolaminated structure are shown in Figure 2.2. The lattice becomes more complex with increasing $n$ value, which reduces the thermodynamic stability of the MAX phase with respect to competing phases. This is well reflected by the range of reported MAX phases: more than 40 belong to the 211 subgroup, followed by six 312 and seven 413 phases, while $\left(\mathrm{Ti}_{0.5} \mathrm{Nb}_{0.5}\right)_{5} \mathrm{AlC}_{4}$ has been synthesized as the first 514 phase very recently [21]. Stackings of $615\left(\mathrm{Ta}_{6} \mathrm{AlC}_{5}\right)$ and $716\left(\mathrm{Ti}_{7} \mathrm{SnC}_{6}\right)$ periodicity have only been observed as inclusions of several c-lattice spacings in high resolution transmission electron microscopy (HRTEM) [22, 23].

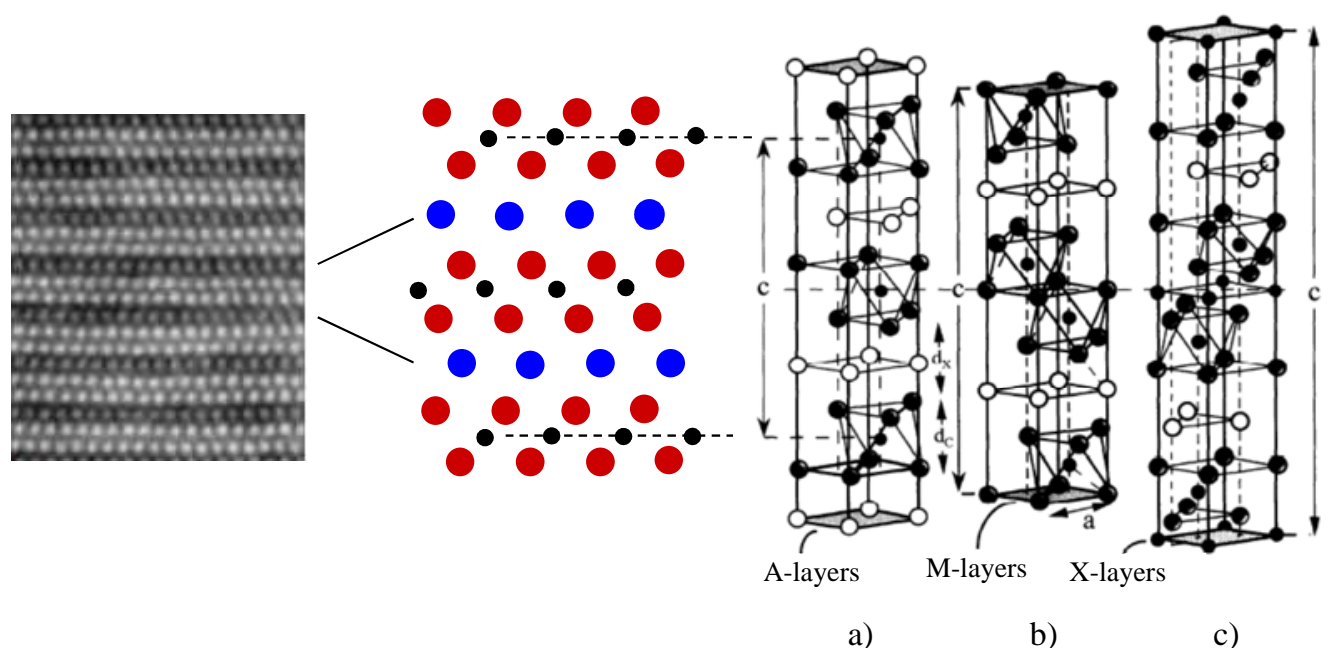

Figure 2.2. Unit cells of a) 211, b) 312, and c) 413 MAX phases [24] and a TEM image of $(\mathrm{Cr}, \mathrm{Mn})_{2} \mathrm{AlC}$ illustrating the characteristic nanolaminated MAX phase structure.

The inherently layered crystal structure together with the presence of metallic $(M-A)$ and covalent $(M-X)$ bonds results in a unique combination of both metallic and ceramic properties. MAX phases are typically good thermal and electrical conductors (e.g., the electrical conductivity of $\mathrm{Ti}_{3} \mathrm{SiC}_{2}$ is double that of pure $\mathrm{Ti}$ [25]), as well as thermodynamically stable at high temperatures, hard, wear- and oxidation resistant. In addition, MAX phases exhibit extreme thermal shock resistance, damage tolerance, and are easily machinable (e.g., can be cut with a manual hacksaw). The latter properties stem from the characteristic deformation mechanism via formation of kink bands, which effectively lock internal delaminations by dislocation walls [see Figure 2.3 a)], hindering the crack growth and subsequent failure on the macroscopic scale. The exceptional damage tolerance of MAX phases is illustrated in Figure $2.3 \mathrm{~b}$ ): surface dents are the only effect of hitting a $\mathrm{Ti}_{2} \mathrm{AlC}$ block with a hammer. 
Moreover, damage tolerance is further enhanced by self-healing behavior, i.e., oxidation induced crack filling [26, 27].
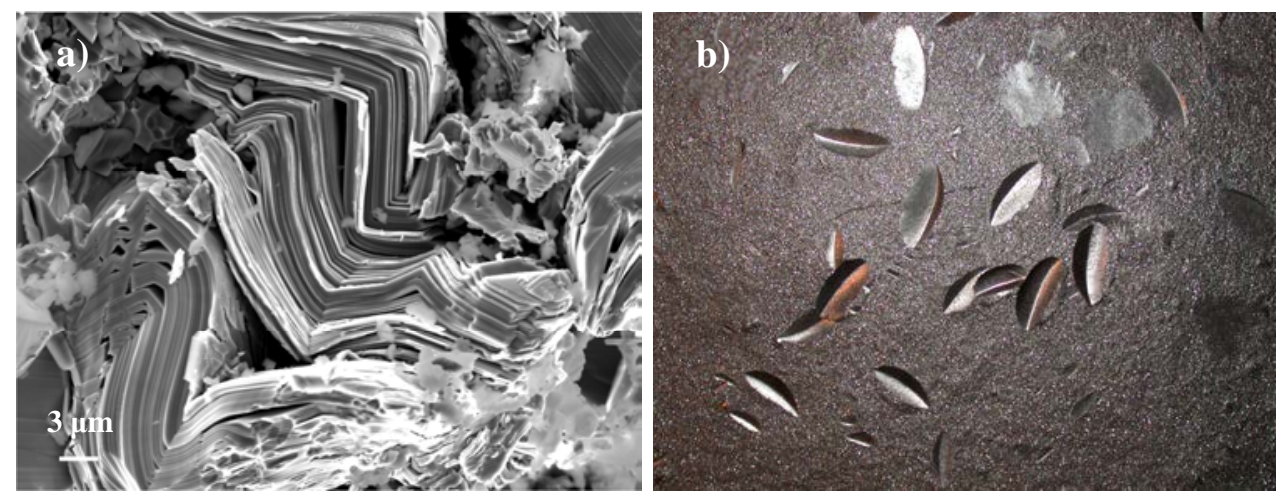

Figure 2.3. a) Characteristic deformation of MAX phases, here illustrated for $(\mathrm{Cr}, \mathrm{Mn})_{2} \mathrm{AlC}$. Note that delamination ends are stopped by kink bands which prevent further growth of the crack. b) Dents on a $\mathrm{Ti}_{2} \mathrm{AlC}$ block left after repeatedly hitting it with a steel hammer (courtesy of 3-ONE-2).

All these characteristics make MAX phases promising candidates for many industrial applications, e.g., as high temperature and/or corrosive environment components, sliding electrical contacts, contacts for 2D electronic circuits, wear protective and lubricant coatings, etc. In fact, the collaboration between scientific and industrial communities has been very close. MAX phase powders were commercialized already in 2001 (only five years after the first publication on the $\mathrm{Ti}_{3} \mathrm{SiC}_{2}$ properties) by 3-ONE-2/Kanthal $\mathrm{AB}$ under the brand names Maxthal211 $\left(\mathrm{Ti}_{2} \mathrm{AlC}\right)$ and Maxthal312 $\left(\mathrm{Ti}_{3} \mathrm{SiC}_{2}\right)$. As $\mathrm{Ti}_{2} \mathrm{AlC}$ is extremely oxidation resistant, gas burner nozzles manufactured from Maxthal211 showed better performance compared to the steel ones [Figure 2.4 a)], and Maxthal211 heating elements were cycled between room temperature and $1350^{\circ} \mathrm{C} 10000$ times with no resulting damage [Figure $2.4 \mathrm{~b}$ )]. Concrete dry drills, where Co in the usual diamond-Co drills has been replaced by Maxthal312 [Figure $2.4 \mathrm{c}$ )], have been tested and experienced considerably less wear. Another example is MAX phases as formers for fully dense and hollow objects [Figure $2.4 \mathrm{~d}$ )]. 


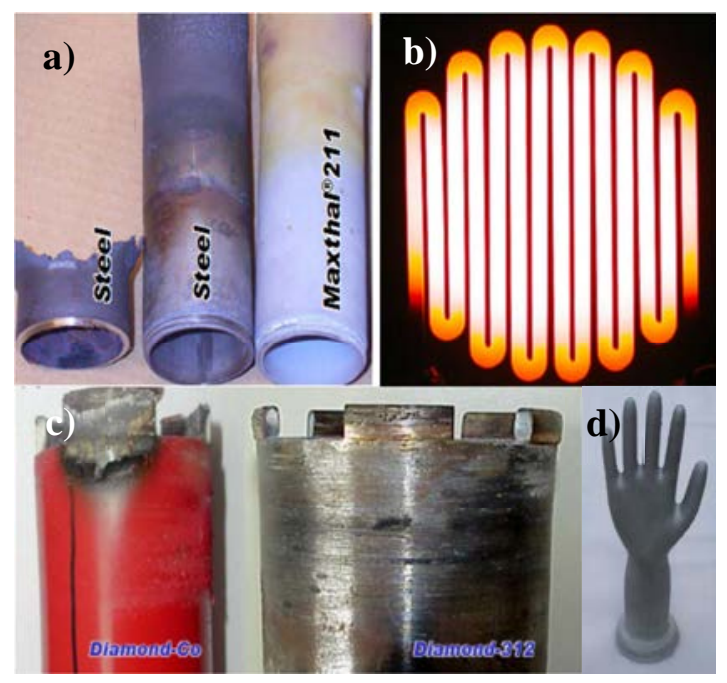

Figure 2.4. Potential applications of MAX phases: a) a gas burner nozzle manufactured from $\mathrm{Ti}_{2} \mathrm{AlC}$ demonstrated longer lifetime compared to the usual steel ones, b) $\mathrm{Ti}_{2} \mathrm{AlC}$ heater at $1350{ }^{\circ} \mathrm{C}$, c) diamond- $\mathrm{Ti}_{3} \mathrm{SiC}_{2}$ concrete dry drill experienced less wear compared to the diamond-Co one, d) a glove former. (Courtesy of 3-ONE-2.)

However, all the above mentioned applications focus on operation on the macroscopic scale. This has been the main direction for investigating and improving MAX phase properties, such as in attempts to increase hardness or conductivity, or in studies on behavior at high temperatures. The highly anisotropic MAX phase structure and its nanolaminated nature is not yet fully taken into advantage, despite potential for new implementations on the nanoscale, as, e.g., magnetic atomic-thin multilayers for possible sensor or spintronics applications.

\subsection{MAX phase alloys}

MAX phases, constituting a family of materials composed of neighboring elements in the periodic table and with the same crystal structure, provide ideal possibilities for alloying. Alloying on $M$ - and $A$-sites has been extensively studied and a large number of MAX phases synthesized, e.g., (Ti,Nb) ${ }_{2} \mathrm{AlC}$ [28], (Ti,Cr) $)_{2} \mathrm{AlC}$ [29], (Cr,V) $)_{2} \mathrm{AlC}$ [29], $\mathrm{Ti}_{3}(\mathrm{Al}, \mathrm{Sn}) \mathrm{C}_{2}$ [30], $\mathrm{Ti}_{3}(\mathrm{Si}, \mathrm{Ge}) \mathrm{C}_{2}$ [31]. Solid solutions on $X$ site have also been investigated, e.g., $\mathrm{Ti}_{2} \mathrm{Al}(\mathrm{C}, \mathrm{N})$ [32] and $\mathrm{Ti}_{3} \mathrm{Al}(\mathrm{C}, \mathrm{N})_{2}$ [30], but alloying possibilities are limited due to only two elements available. The partial replacement of one element by another enables fine tuning of the properties, e.g., hardness or electrical resistance, by properly adjusting the percentage of the substituted atoms. For instance, Vickers hardness of $\mathrm{Ti}_{2} \mathrm{AlC}$ increases linearly from 3.5 to $4.5 \mathrm{GPa}$ as $20 \%$ of $\mathrm{Ti}$ is substituted by $\mathrm{V}$ [33]. In some cases, solid solutions may exhibit superior characteristics compared to the pure constituents, e.g., bulk $\mathrm{Ti}_{2} \mathrm{Al}\left(\mathrm{C}_{0.5} \mathrm{~N}_{0.5}\right)$ has been observed 
to be much harder and stiffer than $\mathrm{Ti}_{2} \mathrm{AlC}$ or $\mathrm{Ti}_{2} \mathrm{AlN}$ [32]. Another interesting example is $\left(\mathrm{V}_{0.5} \mathrm{Cr}_{0.5}\right)_{3} \mathrm{AlC}_{2}$ - neither $\mathrm{V}_{3} \mathrm{AlC}_{2}$ nor $\mathrm{Cr}_{3} \mathrm{AlC}_{2}$ exist separately [34]. This all demonstrates that solid solutions of MAX phases are well worth investigating. However, the substituting elements are often chosen from those used in previously synthesized MAX phases. $M, A$, and $X$ elements outside conventional compositions are likely to provide more pronounced changes in the properties, or even new characteristics. Promising candidates are those neighboring the already tested elements, due to similar atom size and electronic structure. In this Thesis, incorporation of $\mathrm{Mn}$ on the $M$-site and $\mathrm{O}$ on the $X$-site has been investigated.

\subsection{0xygen incorporation}

\subsubsection{Substitution}

Incorporation of $\mathrm{O}$ was first observed in the well-known $\mathrm{Ti}_{2} \mathrm{AlC}$. An initial study showed experimental indications of $\mathrm{O}$ substituting $\mathrm{C}$ while still retaining the MAX phase structure [35], suggesting $\mathrm{O}$ as a potential $X$ element besides $\mathrm{C}$ and N. Subsequent calculations indicated that $\mathrm{O}$ prefers the $\mathrm{C}$ site under oxygen-lean conditions and high temperature [36] and that up to at least 50\% of $\mathrm{C}$ may be replaced by $\mathrm{O}$ [37]. Figure 2.5 shows formation enthalpies $\left(\Delta H_{c p}\right)$ calculated for $\mathrm{Ti}_{2} \mathrm{Al}\left(\mathrm{C}_{1-\mathrm{x}} \mathrm{O}_{\mathrm{x}}\right)$ with respect to various intrinsic defects formed upon $\mathrm{O}$ incorporation, of which $\mathrm{O}$ substitution for $\mathrm{C}\left(S_{O}^{C}\right)$ is the most favored [37]. Supporting experimental evidence on $\mathrm{O}$ taking the $\mathrm{C}$ positions in the lattice was provided by electron energy loss spectroscopy (EELS) combined with theoretical simulations [38]. Formation of $\mathrm{Ti}_{2} \mathrm{Al}(\mathrm{N}, \mathrm{O}) \mathrm{MAX}$ phase with $\mathrm{Al}_{2} \mathrm{O}_{3}$ substrate acting as $\mathrm{O}$ source has also been reported [39]. Furthermore, accommodation of $\mathrm{O}$ on $A$-sites up to 10 at.\% has been observed in highly defected $\mathrm{Ti}_{3} \mathrm{SiC}_{2}$ [40]. However, as a neighboring element for $\mathrm{N}$ and $\mathrm{C}, \mathrm{O}$ is more promising as a substitute on the $X$-site.

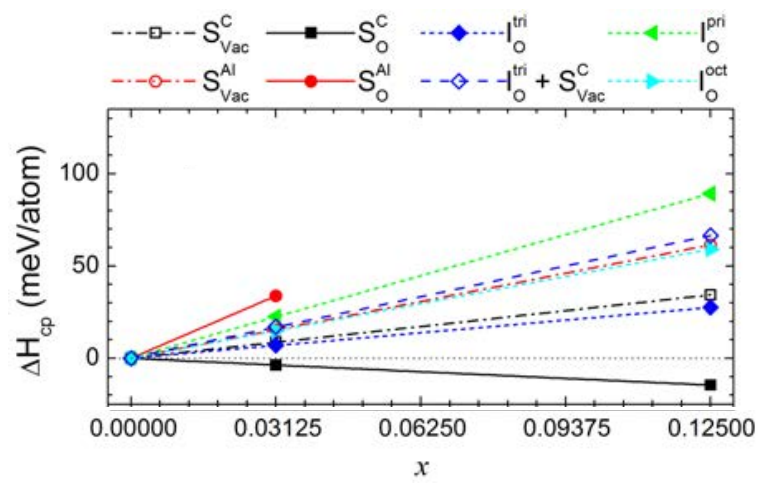

Figure 2.5. Calculated formation enthalpies $\Delta H_{c p}$ for $\mathrm{Ti}_{2} \mathrm{Al}\left(\mathrm{C}_{1-\mathrm{x}} \mathrm{O}_{\mathrm{x}}\right)$ as a function of concentration $x$. Oxygen substitution for carbon $\left(S_{O}^{C}\right)$ is the most favorable of all considered intrinsic defects [37]. 
In this Thesis, the MAX phase oxycarbide $\mathrm{Ti}_{2} \mathrm{Al}\left(\mathrm{C}_{1-\mathrm{x}} \mathrm{O}_{\mathrm{x}}\right)$ has been investigated. A previous theoretical study of the electronic structure of $\mathrm{Ti}_{2} \mathrm{AlC}$ shows anisotropy, with indications of metallic behavior in plane and insulating behavior out of plane (in c-direction) [12]. However, the conductivity along the c-direction has been suggested to change as $\mathrm{C}$ is substituted by $\mathrm{O}$, from insulating, via n-type, to p-type, for an $\mathrm{O}$ concentration up to 12.5 at.\% [12]. Mechanical characteristics are affected as well, e.g., bulk modulus B increases from 140 to $161 \mathrm{GPa}$ as O gradually replaces all $\mathrm{C}$ atoms [41]. Thus, the suggested anisotropic transport properties of $\mathrm{Ti}_{2} \mathrm{AlC}$ may be tuned by adjusting the amount of substitutional $\mathrm{O}$. Therefore, the attainable $\mathrm{O}$ concentration range in $\mathrm{Ti}_{2} \mathrm{Al}\left(\mathrm{C}_{1-\mathrm{x}} \mathrm{O}_{\mathrm{x}}\right)$ has been explored in Paper VI. Incorporation of $\mathrm{O}$ from residual gas and $\mathrm{Al}_{2} \mathrm{O}_{3}$ substrate upon solid-state reaction with understoichiometric $\mathrm{Ti}_{2} \mathrm{AlC}_{1-\mathrm{y}}$ and $\mathrm{TiC}_{\mathrm{z}}$ has consequently been reported, with measured $\mathrm{O}$ concentration up to 13 at.\% [42].

\subsubsection{Interstitials}

Oxygen may also be incorporated as an interstitial in the MAX phase. Calculations show that $\mathrm{O}$ can assume an interstitial position in the $\mathrm{Al}$ layer in both $\mathrm{Ti}_{2} \mathrm{AlC}$ [36] and $\mathrm{Cr}_{2} \mathrm{AlC}$ [43]. Recently, incorporation of 3.5 at.\% interstitial $\mathrm{O}$ in $\mathrm{Cr}_{2} \mathrm{AlC}$ has been reported, which is the first experimentally realized interstitial MAX phase solid solution. It has been suggested that preferred interstitial or substitutional $\mathrm{O}$ incorporation sites in different MAX phases and subsequently formed $A-\mathrm{O}$ or $M-\mathrm{O}$ bonds trigger different mechanisms for oxide formation. This may explain different oxidation behavior in, e.g., $\mathrm{Cr}_{2} \mathrm{AlC}$ and $\mathrm{Ti}_{2} \mathrm{AlC}$ [43], and result in self-healing phenomena.

\subsection{Magnetism}

The magnetic state of a material is very sensitive to the local atomic environment, which in thin film systems may be possible to change in a controlled way. This results in phenomena not observed in the materials' bulk counterparts, such as interfacial stress induced magnetic anisotropy, stabilization of new phases, interlayer exchange coupling, tunnel magnetoresistance, and giant magnetoresistance. These discoveries have revolutionized applications of data storage and magnetic recording as well as created the new field of spintronics.

Magnetic MAX phases would be excellent candidates for layered magnetic materials with strain- and dislocation-free interfaces, as they all exhibit similar in-plane lattice parameters. An advantage originating from the inherent nanolaminated MAX phase structure is the 
possibility to form very thin magnetic layers which would be challenging to obtain artificially. However, the area of magnetic MAX phases is relatively unexplored to date.

Theoretical calculations on traditional MAX phases identify non-magnetic phases, such as $\mathrm{Ti}_{2} \mathrm{AlC}$ and $\mathrm{V}_{2} \mathrm{AlC}$ [44] as well as antiferromagnetic Cr-based phases $\mathrm{Cr}_{2} \mathrm{AlC}$ [44], $\mathrm{Cr}_{2} \mathrm{GeC}$ [45, 46], and $\mathrm{Cr}_{2} \mathrm{GaC}$ [47]. Obtained experimental results, in contrast, show Pauli paramagnetism for $\mathrm{Cr}_{2} A \mathrm{C}(A=\mathrm{Al}, \mathrm{Ge}, \mathrm{Ga})$ [48] as well as $\mathrm{Ti}_{3} \mathrm{SiC}_{2}$ [49] and $\mathrm{Ti}_{3} \mathrm{AlC}_{2}$ [50], which means that the magnetization is linearly proportional to the applied magnetic field. For $\mathrm{Cr}_{2} \mathrm{GaN}$, a spin density wave transition was detected at $170 \mathrm{~K}$ [48]. A ferromagnetic ground state has not been predicted and confirmed, which is in line with the elements forming MAX phases being either paramagnetic or diamagnetic, with the antiferromagnetic $\mathrm{Cr}$ as the only exception. The latter explains the attention almost exclusively directed to $\mathrm{Cr}$-containing MAX phases. Therefore, in order to realize magnetic properties, a new approach must be taken, i.e., incorporation of elements outside those traditionally used to form MAX phases.

Initial attention has been directed towards the hypothetical $M$ element $\mathrm{Fe}$, due to its wellknown ferromagnetic properties and the many ferromagnetic compounds that it forms. Luo et al. predicted $\mathrm{Fe}_{3} \mathrm{AlC}_{2}$ to be stable and ferromagnetic with a magnetic moment of $0.73 \mu_{\mathrm{B}}$ per Fe atom ( $\mu_{\mathrm{B}}-$ Bohr magneton) [16]. However, a recent theoretical study by Dahlqvist et al. identifies a different set of the most competing phases in the Fe-Al-C system, which results in positive formation enthalpy of $\mathrm{Fe}_{3} \mathrm{AlC}_{2}(\Delta H=0.25 \mathrm{eV} /$ atom $)$, and thus thermodynamic instability [15]. The same study suggests $(\mathrm{Cr}, \mathrm{Mn})_{2} \mathrm{AlC}$ as a stable and potentially magnetic MAX phase, with magnetic moment gradually increasing with Mn content. The material is expected to possess either ferromagnetic or antiferromagnetic properties, depending on the $\mathrm{Cr}$ and $\mathrm{Mn}$ atomic configuration on the $M$-sublattice. The Curie temperature is roughly estimated to being close to, or above, room temperature [15].

Although paramagnetic in its elemental form, Mn has unfilled 3d-shell allowing exchange interaction when combined with other elements, resulting in, e.g., ferromagnetic or antiferromagnetic properties of the compound. One such example is the Mn-based antiperovskite structural compounds, $\mathrm{Mn}_{3} A X$ ( $A=$ metal or semiconducting elements and $X=\mathrm{C}$ or $\mathrm{N}$ ), which have attracted considerable attention due to their electrical and magnetic transport properties [51], with a magnetic state and transition temperature strongly affected by $A$ element doping [52].

Inspired by the above mentioned theoretical predictions by Dahlqvist et al. [15], (Cr,Mn) ${ }_{2} \mathrm{AlC}$ has been synthesized as the first Mn-containing MAX phase (Paper I), and subsequently characterized with respect to its magnetic properties (Paper III). The vibrating sample 
magnetometry (VSM) results indicate a ferromagnetic or antiferromagnetic ground state, with a transition temperature well above room temperature, [Figure 2.6 a)].

Furthermore, Mn incorporation has been expanded to the neighboring MAX phase systems of $\mathrm{Cr}_{2} \mathrm{GeC}$ (Paper II) and $\mathrm{Cr}_{2} \mathrm{GaC}$ (Paper V). (Cr,Mn) $)_{2} \mathrm{GeC}$ exhibited a magnetic signal up to at least $300 \mathrm{~K}$ [Figure $2.6 \mathrm{~b}$ )]. The saturation magnetic moment per $\mathrm{Mn}$ atom has been determined to $0.36 \mu_{\mathrm{B}}$ at $50 \mathrm{~K}$, which is $\sim 1 / 6$ of that predicted from calculations. The discrepancy is ascribed to possible presence of competing ferromagnetic and antiferromagnetic interaction, which is consistent with the theoretically expected close to degenerate ground state.

Initial characterization of magnetism in $(\mathrm{Cr}, \mathrm{Mn})_{2} \mathrm{GaC}$ showed transition temperatures not corresponding to any of the known magnetic phases in the $\mathrm{Cr}-\mathrm{Mn}-\mathrm{Ga}-\mathrm{C}$ system, indicating $(\mathrm{Cr}, \mathrm{Mn})_{2} \mathrm{GaC}$ as being magnetic. There exists a previous report on synthesis and attempts to measure $(\mathrm{Cr}, \mathrm{Mn})_{2} \mathrm{GaC}$ magnetic properties [18]. The reported results are, however, nonconclusive, due to limited phase analysis and lack of composition analysis of the actual MAX phase. Furthermore, the suggested antiferrimagnetism is based on a tiny anomaly at low magnetic field.

The reported $\mathrm{Mn}$ content in $(\mathrm{Cr}, \mathrm{Mn})_{2} \mathrm{AlC}$ and $(\mathrm{Cr}, \mathrm{Mn})_{2} \mathrm{GeC}$ thin films is 10 and 12.5 at.\%, respectively, while in $(\mathrm{Cr}, \mathrm{Mn})_{2} \mathrm{AlC}$ and $(\mathrm{Cr}, \mathrm{Mn})_{2} \mathrm{GaC}$ bulk material it is 3 and 15 at.\%, respectively. Very recently, the first purely Mn-based MAX phase, $\mathrm{Mn}_{2} \mathrm{GaC}$, was predicted stable based on theoretical calculations, and subsequently synthesized in thin film form. Magnetic measurements showed ferromagnetic response with hysteresis observed up to and including $230 \mathrm{~K}$ [Figure $2.6 \mathrm{c}$ )]. The saturation magnetic moment per $\mathrm{Mn}$ atom was determined to $0.29 \mu_{\mathrm{B}}$ at $50 \mathrm{~K}$ [17].
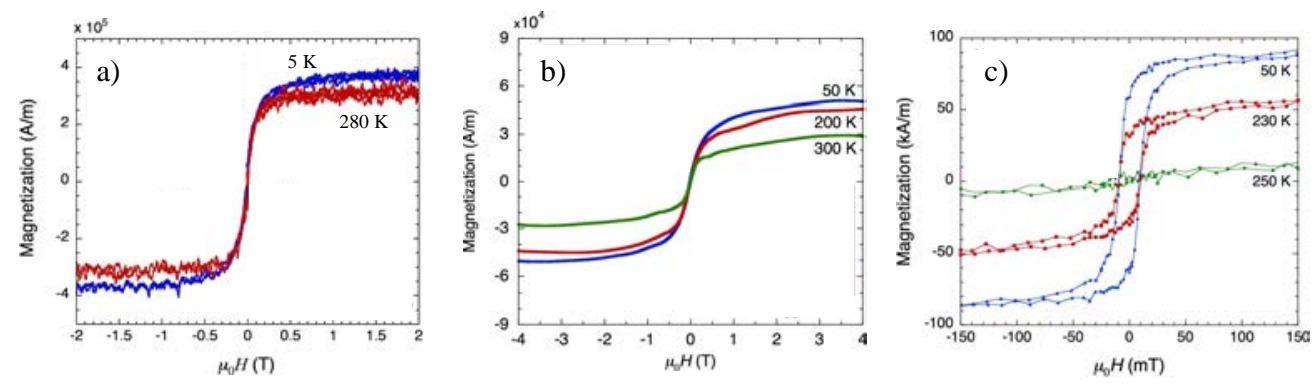

Figure 2.6. The magnetic response measured with VSM for a) $\left.(\mathrm{Cr}, \mathrm{Mn})_{2} \mathrm{AlC}, \mathrm{b}\right)(\mathrm{Cr}, \mathrm{Mn})_{2} \mathrm{GeC}$, and c) $\mathrm{Mn}_{2} \mathrm{GaC}$ [17]. 
Evidently, the incorporation of Mn has been the turning point in magnetic MAX phase research. Three magnetic MAX phase systems have been discovered in one year, and Mn has been identified as a new $M$ element in the MAX phase family. The results obtained so far are very encouraging and provide the foundation for future advancements in this research area. 



\section{Materials synthesis}

Most vacuum based thin film synthesis techniques can be divided into two groups: chemical vapor deposition (CVD) and physical vapor deposition (PVD). PVD involves purely physical processes such as atoms/ions being released from a target with subsequent condensation on a substrate. CVD growth occurs through chemical reactions between volatile precursors on a surface, which often require high temperature and therefore limit the choice of substrate material.

Two PVD techniques have been used in this Thesis: pulsed cathodic arc and magnetron sputtering.

\subsection{Cathodic arc}

The principle behind cathodic arc is a discharge between a cathode (target) and an anode. A microexplosion on the cathode surface creates a pool of molten material, called an arc spot, from which cathode material is emitted. The resulting plasma has a high degree of ionization (close to 100\%), including presence of multiply charged ions with inherent high ion energies, ranging up to $\sim 150 \mathrm{eV}$. A high ionization degree is advantageous through the availability of manipulating the plasma by electric or magnetic fields. This is beneficial in terms of process control, and allows deposition of stable as well as metastable phases.

In order to ignite and sustain a stable arc discharge, the cathode material must be conductive. There have been attempts to overcome the difficulties posed by semiconducting cathodes, 
e.g., Si and Ge, by heavy doping [53] and cathode pre-heating [54]. However, use of elemental cathodes of these materials remains challenging and limited.

An arc discharge is a violent process (can be imagined as thousands of volcano eruptions on the micro-scale), in which not only atoms/ions/electrons are emitted, but also cathode material in the form of microdroplets. These adhere to the growing film, resulting in reduced crystal quality, non-uniform composition, and a rough surface. To suppress droplet formation and hinder their arrival to the growth zone, reduction (steered arc, pulsed arc) or removal (shaded arc, filtered arc) techniques are used. A combination of these techniques is also common.

Cathodic arc may be used in two different modes: continuous direct current (DC) and pulsed. DC arc is widely employed for industrial applications due to the high growth rates and the realized large-scale deposition systems. Pulsed arc is beneficial for an improved and flexible control of the film composition, as less than a monolayer of the cathode material can be released in each pulse (e.g., growth rate of $\mathrm{Al}$ is $\sim 0.3 \AA /$ pulse). This allows fine adjustment of the plasma composition, and, in turn, precise control of the growing film stoichiometry.

A triple cathode high current pulsed cathodic arc (SPArc) has been used to grow the $\mathrm{Ti}_{2} \mathrm{Al}(\mathrm{C}, \mathrm{O})$ and $(\mathrm{Cr}, \mathrm{Mn})_{2} \mathrm{AlC}$ thin films investigated in this Thesis. A schematic of the system as well as an image of the cathodic arc deposition chamber at Linköping University is presented in Figure 3.1.

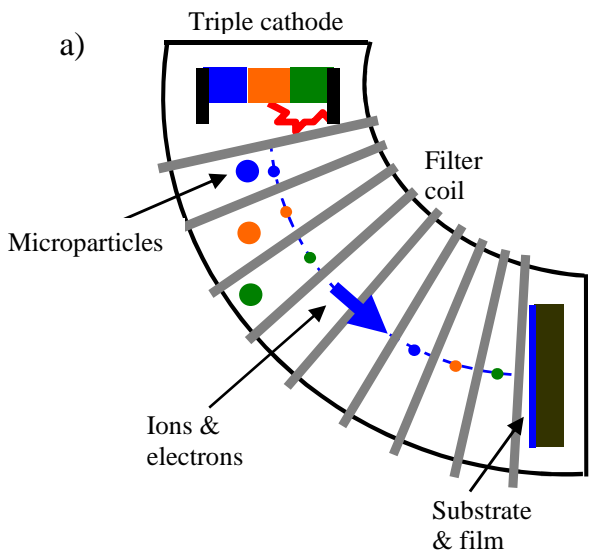

b)

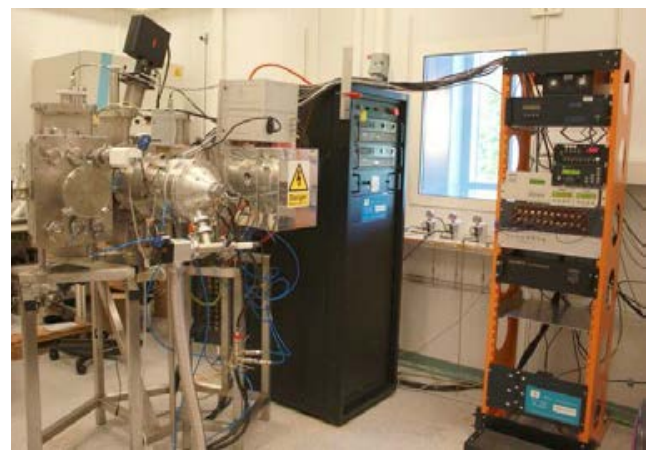

Figure 3.1. a) Schematic of the pulsed cathodic arc source used in this work, and b) a picture of the pulsed arc deposition system (SPArc) at Linköping University. 
Center triggering was used to ignite the arc [55], and the pulse length was adjusted for each cathode individually to ensure effective use of the cathode material as the arc spots move from the center to the edges. Figure 3.2 shows a new and a used Ni cathode.

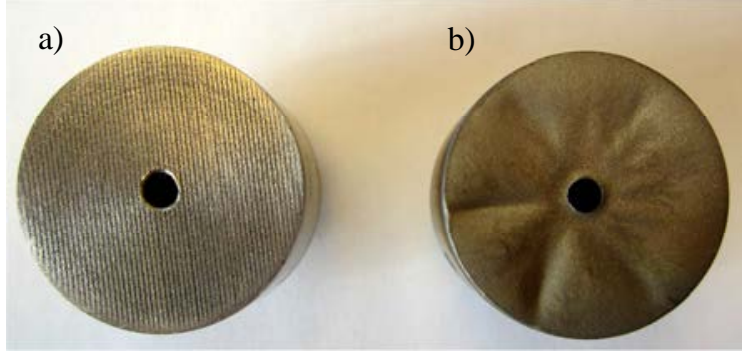

Figure 3.2. Ni cathodes: a) new, and b) used. Note severe surface erosion caused by preferred arc spot tracks.

A curved magnetic filter was employed to remove microdroplets from the plasma plume. The magnetic field lines guide the electrons towards the substrate, and the ions follow due to Coulomb attraction and the constraint of a quasineutral plasma. Neutral microdroplets, on the other hand, continue their straight path towards the chamber walls.

\subsection{Magnetron sputtering}

Magnetron sputtering, compared to pulsed arc, is a gentle deposition technique. In pulsed arc, material from the cathode is released through microexplosions, leaving the cathode surface highly eroded. In magnetron sputtering, the atoms are comparatively gently ejected from the target material under the bombardment of inert gas ions, most often Ar, yielding atom energies in the range of a few $\mathrm{eV}$.

A schematic of a typical magnetron sputtering deposition system is presented in Figure 3.3. Ar gas is let into the chamber, and Ar atoms are ionized under collisions with other Ar atoms or secondary electrons. A negative bias is applied to the target to accelerate the $\mathrm{Ar}^{+}$ions towards it, and as the ions hit the target, atoms are knocked out (sputtered). Atoms ejected from the target are transported in the vacuum chamber and condense onto the substrate to form a film.

To initiate and sustain a sputtering discharge, a relatively high Ar partial pressure is needed. This is unfavorable, as target atoms are scattered under their way towards the growth zone and thus the deposition rate is reduced. Furthermore, processes at the substrate surface, e.g., 
adatom mobility, are limited, resulting in a reduced crystal quality of the film. The Ar pressure can be decreased by increasing the Ar ion concentration in the vicinity of the target surface, realized by placing magnets underneath the target. Secondary electrons are then trapped by the magnetic field lines and the ionization degree of Ar atoms close to the target is thus increased. A higher concentration of Ar ions at the target area leads to higher sputtering rate, which in turn leads to an increased growth rate of the film.

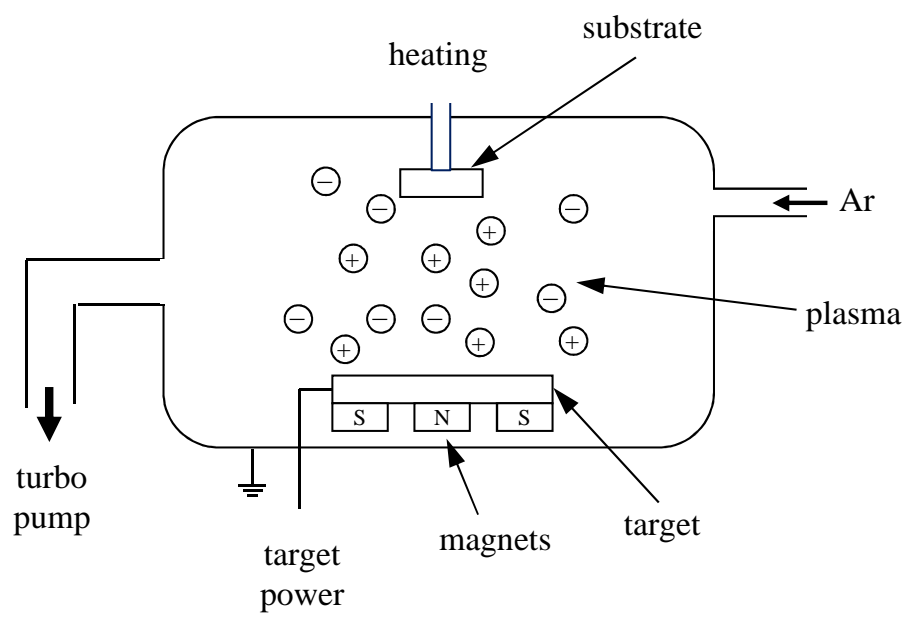

Figure 3.3. Schematic of a magnetron sputtering system.

In this Thesis three magnetron sputtering systems have been used:

- $(\mathrm{Cr}, \mathrm{Mn})_{2} \mathrm{AlC}$ films have been deposited in a 4 target magnetron sputtering system in the Materials Chemistry Group at RWTH Aachen University (Germany) [Figure 3.4 a)].

- $(\mathrm{Cr}, \mathrm{Mn})_{2} \mathrm{GeC}$ and $(\mathrm{Cr}, \mathrm{Mn})_{2} \mathrm{AlC}$ films have been deposited in a 3 target magnetron sputtering system in the Thin Film Physics Division at Linköping University [Figure $3.4 \mathrm{~b})$ ].

- $(\mathrm{Cr}, \mathrm{Mn})_{5} \mathrm{Al}_{8}$ films have been deposited in a 5 target magnetron sputtering system in the Thin Film Physics Division at Linköping University [Figure 3.4 c)]. 
a)

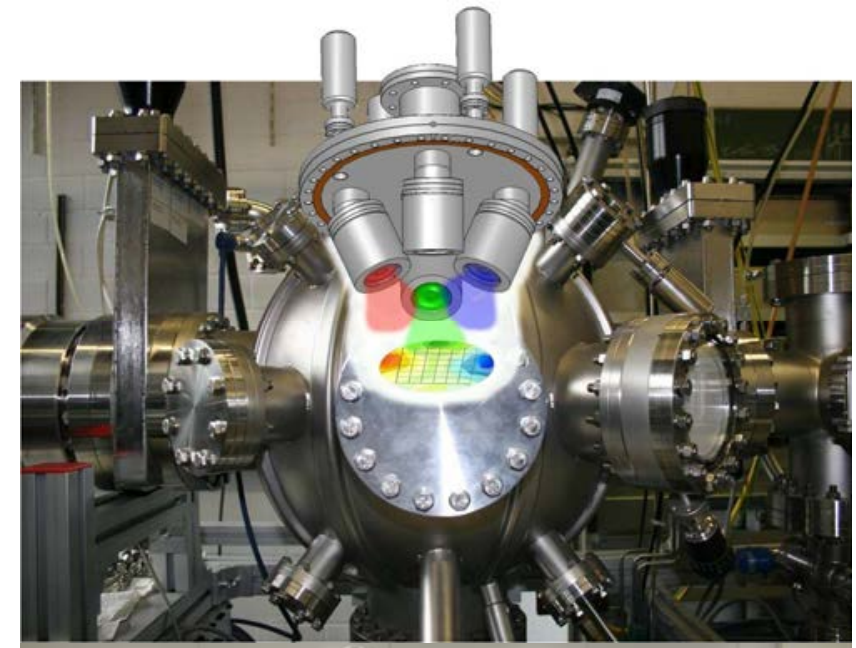

b)

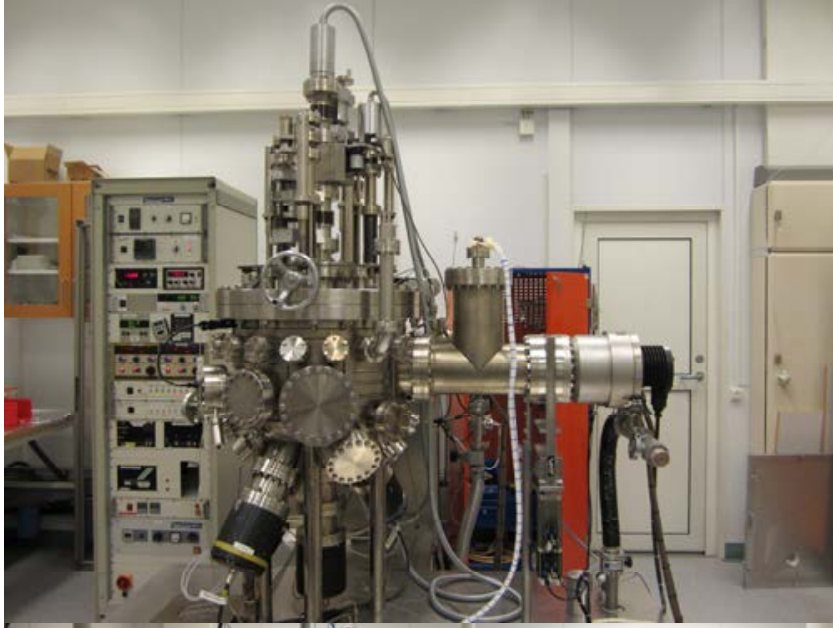

c)

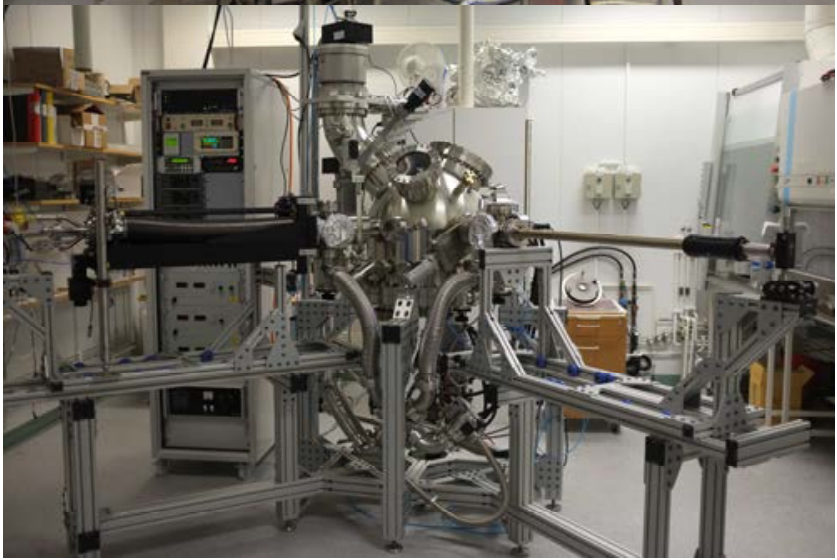

Figure 3.4. Magnetron sputtering systems used in this work for depositions of a) $(\mathrm{Cr}, \mathrm{Mn})_{2} \mathrm{AlC}$ (courtesy of T. Takahashi), b) $(\mathrm{Cr}, \mathrm{Mn})_{2} \mathrm{GeC}$ and $(\mathrm{Cr}, \mathrm{Mn})_{2} \mathrm{AlC}$, and c) $(\mathrm{Cr}, \mathrm{Mn})_{5} \mathrm{Al}_{8}$ (courtesy of I. Zhirkov). 


\subsection{Plasma-surface interaction during thin film synthesis}

As the plasma reaches the substrate, atoms adsorb on the surface forming two or three dimensional islands, which grow and eventually coalesce to form a continuous film. Depending on the interaction between film/film and film/substrate atoms, the growth can be classified into three characteristic modes, see Figure 3.5: layer-by-layer (also called Frank van der Merve) growth, island (or Volmer-Weber) growth, and Stranski-Krastanov (layer-by-layer followed by island) growth.

a)

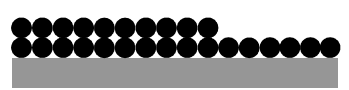

b)

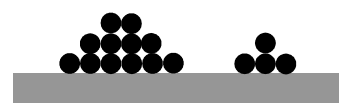

c)

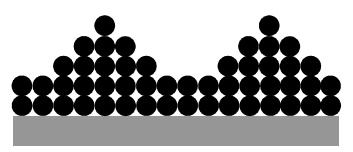

Figure 3.5. Thin film growth modes: a) layer-by-layer (or Frank van der Merve), b) island (or VolmerWeber), and c) Stranski-Krastanov.

Incoming species tend to minimize the total interfacial energy by arranging themselves in a specific crystallographic relation with the substrate. Such extended growth on a crystalline substrate is called epitaxial growth. Epitaxial growth is often intentionally supported by choice of substrate, e.g., $\mathrm{Al}_{2} \mathrm{O}_{3}(0001)$ and $\mathrm{MgO}(111)$ are the most common substrates for the growth of (000n)-oriented MAX phase thin films. The epitaxial relation may be further improved by depositing a so called seed layer directly onto the substrate, prior to growing a film.

It should be noted, that the composition of the plasma and the composition of the resulting film is often non-equivalent. Different species have different sticking coefficients, which also may vary depending on the choice of substrate, growth temperature, etc. Light atoms can be resputtered from the film surface by the heavier ones. It has been noted, e.g., that the number of $\mathrm{Al}$ pulses in arc growth of $\mathrm{Ti}_{2} \mathrm{AlC}$ must be set somewhat higher than inferred from initial calibration [56], which is most likely the result of a lower Al sticking coefficient at higher temperatures combined with resputtering caused by Ti. Furthermore, if a compound target is used, the composition of the film is not necessary the same as that of the target, at least in part due to different angular distributions of the sputtered elements. For example, magnetron sputtering from a single $\mathrm{Ti}_{3} \mathrm{SiC}_{2}$ target resulted in highly off-stoichiometric films with $\geq 50$ at.\% C [57].

Besides the plasma composition, sticking coefficient, and effects from resputtering, the surface atom mobility strongly influences what phases will nucleate on the substrate. 
Sufficient diffusion lengths allow the atoms to acquire the positions of lowest energies and to form large grains of the most energetically favorable phases. The surface mobility is most often enhanced by heating the substrate. Relatively high temperatures $\left(450-1000{ }^{\circ} \mathrm{C}\right)$ are required for growth of MAX phase thin films. At lower temperatures, the diffusion length is shorter which results in numerous small grains as well as considerable amount of competing phases. Amorphous films form closer to room temperature, as the atoms tend to stick to the surface in the positions where they arrive. However, if the samples are subsequently annealed, atoms may gain enough energy to rearrange into more complex structures, and amorphous/nanocrystalline films may transform into single crystal material.

It is well known, that thin film synthesis is a complex process, depending on a large number of parameters. These must be finely controlled and adjusted to yield thin films of high crystal quality.

\subsection{Bulk synthesis}

In bulk synthesis, also referred to as sintering, powder is densified to attain a desired composition and microstructure. Sintering is based on atom diffusion and chemical reactions between the components. The process can be divided into two types: solid state sintering and liquid phase sintering. In solid state sintering, the constituents remain in solid state throughout the synthesis, while in liquid sintering at least one of the components is in the liquid state at the sintering temperature.

The major variables affecting the resultant bulk material may be divided into material variables and process variables. The latter include, e.g., temperature, pressure, heating and cooling rates, and atmosphere. Powder composition, purity, particle size and shape, and particle size distribution are some of the materials variables. Particle size distribution is described by using mesh sizes, e.g., "-325 mesh powder" means that $>90 \%$ of the particles pass through a 325 mesh sieve, which corresponds to a particle size of $44 \mu \mathrm{m}$.

Powders are often pressed simultaneously to a heat treatment, to increase the contact area of the particles and enhance the reaction rate, as well as to increase the driving force for densification. Pressureless sintering, on the other hand, is less expensive and scalable, which makes it applicable for commercial purposes.

A variety of methods exists for bulk synthesis, e.g., spark plasma sintering, hot isostatic pressing, mechanical alloying, etc. In this Thesis, cold pressing of powders and subsequent 
heat treatment under Ar flow, as well as pressureless reaction in vacuum, have been used to synthesize $(\mathrm{Cr}, \mathrm{Mn})_{2} \mathrm{AlC}$ and $(\mathrm{Cr}, \mathrm{Mn})_{2} \mathrm{GaC}$ MAX phases, respectively. Fully dense $(\mathrm{Cr}, \mathrm{Mn})_{2} \mathrm{AlC}$ samples were obtained by hot pressing.

Bulk synthesis in the work of this Thesis has been performed in the MAX Phase and MXene Research Group at Drexel University (USA).

\subsubsection{Pressureless sintering}

- $(\mathrm{Cr}, \mathrm{Mn})_{2} \mathrm{AlC}$ has been synthesized under atmospheric pressure in a tube furnace, using constant flow of Ar as a protective gas to inhibit oxidation. Figure 3.6 a) shows schematic of the experimental set-up.

- $(\mathrm{Cr}, \mathrm{Mn})_{2} \mathrm{GaC}$ has been synthesized under vacuum, with Ga pellets placed on top of a powder mixture. Figure $3.6 \mathrm{~b}$ ) shows schematic of the experimental set-up.

a)

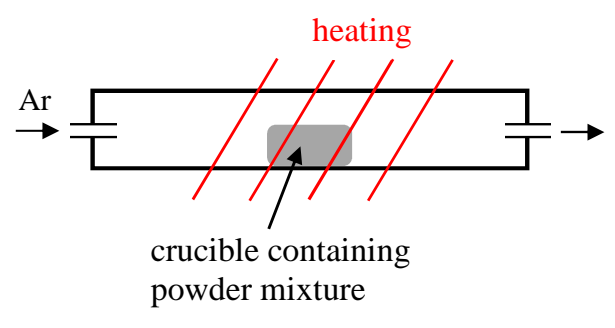

b)

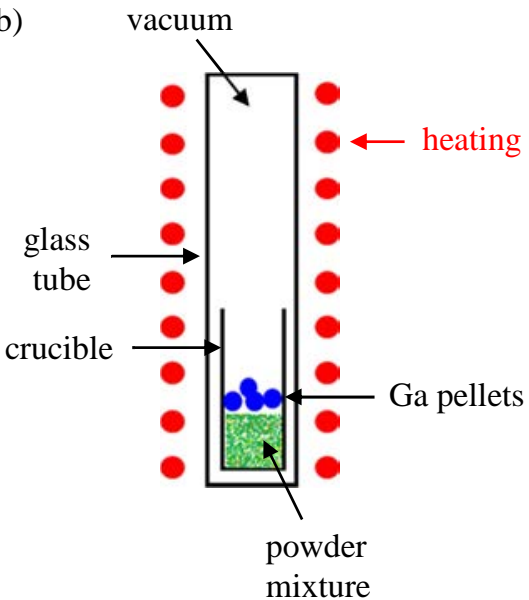

Figure 3.6. Schematics of equipment used for bulk synthesis of a) $(\mathrm{Cr}, \mathrm{Mn})_{2} \mathrm{AlC}$, and b) $(\mathrm{Cr}, \mathrm{Mn})_{2} \mathrm{GaC}$.

\subsubsection{Hot pressing}

Sintering kinetics, besides temperature, depends strongly on applied pressure. Mechanical pressure combined with the heat treatment has the main advantage of promoting densification and reducing the amount of structural flaws, such as microvoids and cracks. Consequently, defect-dependent properties, e.g., mechanical strength and fracture toughness, can be improved. Pressure may also be used to influence the preferred orientation of grain growth. 
In hot pressing, the powder is contained in a die and pressed by oppositely moving punches. It should be kept in mind that contact with the pressing tools, typically made of graphite, may give rise to unwanted chemical reactions and carbon contamination. In order to prevent oxidation, hot pressing is often performed in vacuum or inert gas atmosphere.

- Fully dense $(\mathrm{Cr}, \mathrm{Mn})_{2} \mathrm{AlC}$ has been synthesized in a uniaxial hot press. Figure 3.7 shows the experimental equipment.
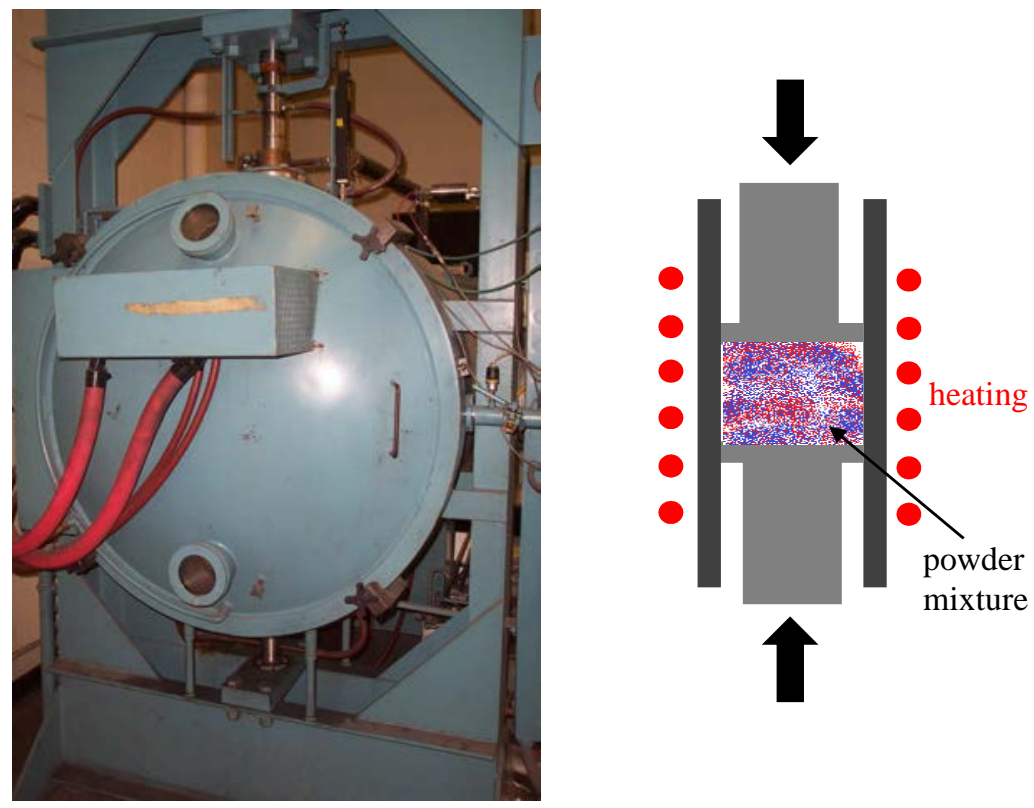

Figure 3.7. Uniaxial hot press used to synthesize fully dense $(\mathrm{Cr}, \mathrm{Mn})_{2} \mathrm{AlC}$ and corresponding schematic.

\subsubsection{Materials formation during bulk synthesis}

The driving force for sintering is a reduction in total interfacial energy of the system. This occurs via two fundamental phenomena: densification and grain growth. Densification lowers the total energy by decreasing the surface area and by replacing solid-vapor interfaces by lower energy solid-solid interfaces. The reduction in energy is higher for smaller radius of curvature, and therefore powders based on smaller particles result in enhanced synthesis rate. In grain growth, the average grain size increases via grain boundary motion and Ostwald ripening. Figure 3.8 illustrates the densification and grain growth processes. Properties of a synthesized powder compact are highly dependent on its microstructure. Therefore, control of densification and grain growth processes is of high technical importance. 


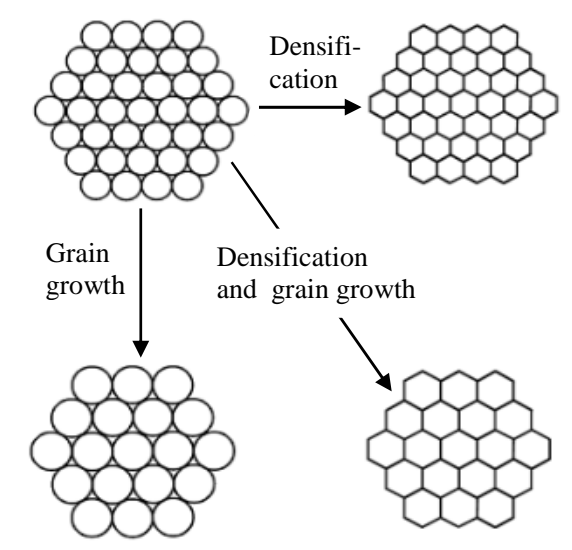

Figure 3.8. Basic phenomena occurring during sintering. Adapted from [58].

\subsection{Advantages and limitations of bulk and thin film synthesis}

One fundamental difference between bulk synthesis and thin film growth is that bulk synthesis is a thermodynamical equilibrium process, while thin film growth can occur far from equilibrium (except for CVD and thin film formation via solid-state reactions). In the formation of thin films, diffusion of adatoms can be enhanced by providing energy not only through substrate heating, but also by, e.g., highly energetic plasma flux or ion bombardment. Therefore, thin films can be synthesized at lower temperatures compared to corresponding bulk material, as bulk synthesis methods require elevated temperatures for complete phase formation and densification. Typically, bulk MAX phases form in the temperature range of $1200-1800{ }^{\circ} \mathrm{C}$, while for thin films the range is $450-1000{ }^{\circ} \mathrm{C}$. Furthermore, the nonequilibrium conditions attainable in thin film growth enable realization of metastable phases and enhanced solubility limits.

Bulk synthesis is a more crude process compared to thin film synthesis. Bulk samples are polycrystalline and often with high defect concentrations, such as inclusions of other phases, unreacted starting components, impurity atoms, grain boundaries, etc. These all affect any measured values of the materials' properties. For example, hardness reported for bulk and thin film samples differ drastically, e.g., $5 \mathrm{GPa}$ [59] and $24 \mathrm{GPa}$ [60], respectively, for $\mathrm{Ti}_{3} \mathrm{SiC}_{2}$. Also, investigations of anisotropic properties are more challenging for bulk materials, as measurements should ideally be performed on single grains of known orientation. Therefore, the material's intrinsic properties may preferably be determined by investigating thin films, which can be produced phase pure and closer to the idealized defect-free crystal compared to 
corresponding bulk samples. However, regarding anisotropy, thin films are often textured, which can limit the access to certain crystal orientations. 



\section{Materials}

\section{characterization}

\section{techniques}

In order to find optimal experimental conditions for specific materials synthesis, iterative feedback is needed on the sample's elemental composition, phases present, crystal orientation, crystal quality, physical properties, etc. In this Thesis work, the following characterization techniques have been used.

\subsection{X-ray diffraction}

$\mathrm{X}$-ray diffraction (XRD) is a simple and non-destructive analysis technique which provides means to identify different phases and their distribution in the sample, as well as texture, average grain size, internal stress, etc.

X-rays are electromagnetic waves with wavelength $(\lambda=[0.5-50] \AA)$, comparable to atomic separation distances. When propagating through a crystal, the X-rays interact with the lattice and are diffracted according to the Bragg's law

$2 d \sin \theta=n \lambda$ 
where $d$ is the atomic spacing, $\theta$ is the scattering angle, $n$ is an integer number, and $\lambda$ is the wavelength.

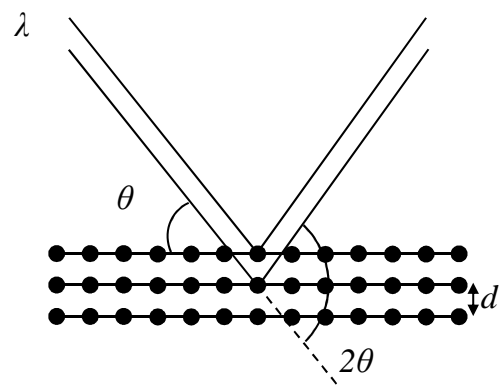

Figure 4.1. Schematic illustration of XRD and a $\theta-2 \theta$ configuration.

As the combination of constituent atoms, crystal structure, and lattice constants is different for different materials/phases, XRD provides with a unique set of diffraction angles and diffracted beam intensities, which makes phase identification possible. Measurements in $\theta-2 \theta$ configuration (detection angle twice as large as incidence angle, see Figure 4.1) are most common. In a symmetric $\theta-2 \theta$ scan, only lattice planes oriented parallel to the surface are probed. For polycrystalline samples, where grains are randomly oriented, peaks from all crystallographic planes are observed. Thin films, on the other hand, are often highly textured, which leaves peaks only from certain planes present. In case of epitaxial MAX phase films grown with c-axis perpendicular to the substrate surface, the peaks correspond to the so called (000n) basal planes. An XRD scan of a (000n)-oriented (Cr,Mn) ${ }_{2}$ AlC MAX phase thin film is presented in Figure 4.2, with marked peaks originating from the basal planes.

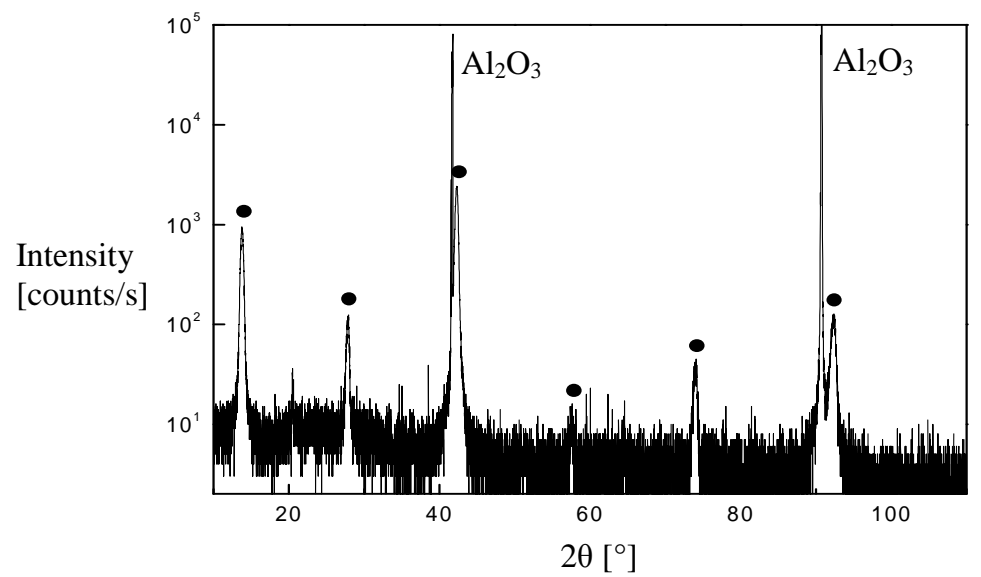

Figure 4.2. XRD $\theta-2 \theta$ scan of $(\mathrm{Cr}, \mathrm{Mn})_{2} \mathrm{AlC}$ MAX phase deposited on $\mathrm{Al}_{2} \mathrm{O}_{3}(0001)$ substrate. Peaks originating from the basal planes of the MAX phase are marked with filled circles. 
In a $\theta-2 \theta$ configuration, only a subset of the grains is monitored. In order to get an orientation distribution of the grains, pole measurements are performed. In a pole measurement, the $2 \theta$ angle is fixed, corresponding to the atomic spacing of interest, while a tilt angle $\chi$ and an azimuthal angle $\varphi$ are varied. Figure 4.3 shows a schematic configuration for a pole measurement. The intensity of a Bragg reflection $(I)$ is recorded as a function of $(\chi, \varphi)$. The most common way to present the data is circular maps of $I(\chi, \varphi)$, so called pole figures. Randomly oriented grains provide intensity at all $\varphi$ angles, which in a pole figure is displayed as circles for a specific $\chi$. In highly textured samples, the intensity peaks are observed as spots for well-defined values of $\varphi$. In addition to texture information, pole figures also provide the crystallographic relation between the film and the substrate. Furthermore, they can be used to determine the crystal structure of phases present.

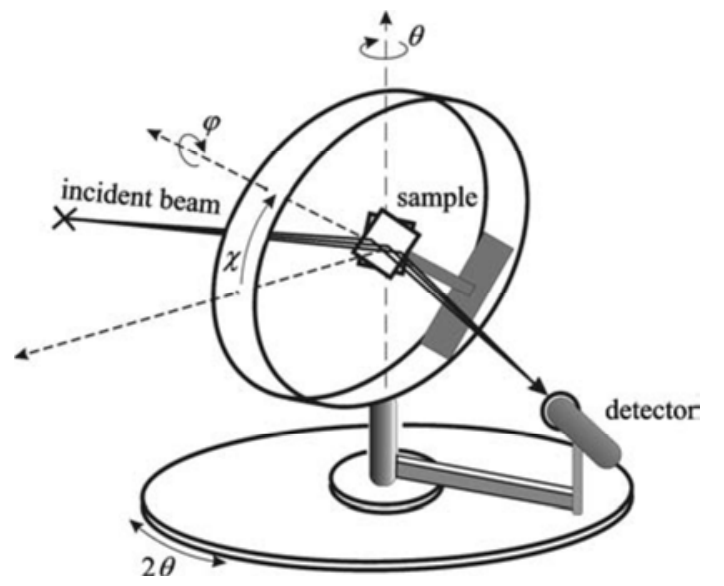

Figure 4.3. Schematic illustration of a pole figure measurement configuration [61].

\subsection{X-ray reflectivity}

$\mathrm{X}$-ray reflectivity (XRR) is based on interference between X-rays reflected from the film surface and from the film/substrate interface in a grazing incidence $\mathrm{X}$-ray beam configuration. XRR provides information on film thickness and multilayer periodicity, surface and interface roughness, as well as density.

The sample requirements for XRR analysis include a smooth film surface and smooth interfaces, a sufficiently thin film, and a difference in electron densities between the film and the substrate. 


\subsection{Scanning electron microscopy}

Scanning electron microscopy (SEM) is an extensively used materials characterization technique, primarily employed for studies of surface topography. A focused electron beam is continuously scanned across a sample surface. As the beam hits the sample, secondary electrons are generated and different electron yields from different surface features result in topographic information. A large depth of field is characteristic for SEM, i.e., objects at different heights are in focus at the same time, particularly advantageous in analysis of fractured samples. The broad magnification range covers the interval from x10 to x 100000 , with a resolution down to a few $\mathrm{nm}$. Figure 4.4 shows an SEM image of a $(\mathrm{Cr}, \mathrm{Mn})_{2} \mathrm{AlC}$ revealing partly coalesced islands.

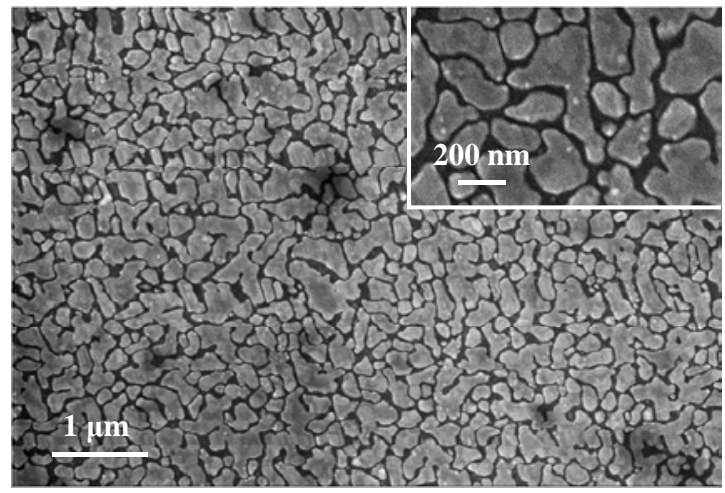

Figure 4.4. SEM image of a (Cr,Mn $)_{2} \mathrm{AlC}$ film constituted of partly coalesced islands.

SEM is often equipped with detectors for analysis of, e.g., backscattered and Auger electrons, $\mathrm{X}$-rays, and photons emitted in photoluminescence. This provides additional information on sample composition and electronic structure.

\subsection{Transmission electron microscopy}

Transmission electron microscopy (TEM) is an invaluable analysis technique for materials investigation on the nanoscale.

The working principle of TEM is very similar to a conventional optical microscope, though with electrons used instead of visible light. The wavelength of highly energetic electrons (e.g., an acceleration voltage of $200 \mathrm{kV}$ results in $\lambda=2.5 \mathrm{pm}$ ) is considerably shorter than the wavelength of visible light $(400-750 \mathrm{~nm})$. This leads to a much higher point resolution (down to $\sim 1 \AA$ ), enabling investigation of sample features on the atomic level. 
Conditions for direct lattice observation are called high-resolution (HR) or scanning (S) TEM imaging. Figure 4.5 represents a HRTEM image of a $(\mathrm{Cr}, \mathrm{Mn})_{2} \mathrm{GeC} \mathrm{MAX}$ phase.

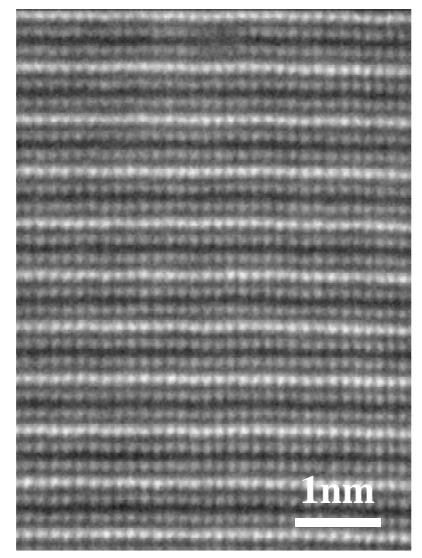

Figure 4.5. Aberration corrected HRTEM image of a $(\mathrm{Cr}, \mathrm{Mn})_{2} \mathrm{GeC}$ MAX phase.

The interaction between the electron beam and the sample in a TEM is non-trivial. Besides transmission, electrons experience absorption, diffraction, and scattering. Furthermore, Auger and secondary electrons are emitted, and X-rays are generated. Analysis of these signals can be used to extract information on the sample composition, impurities present, and the nature of bonding between the atoms. This is often combined with a scanning mode to obtain maps of corresponding analysis for a selected area.

Although TEM is generally a non-destructive technique, the conventional thin film sample preparation for TEM analysis requires sample cutting, grinding, and ion beam milling in order to create electron transparent (thickness $<100 \mathrm{~nm}$ ) regions. Alternatively, a TEM-sample can be prepared by focused ion beam (FIB), which is more expensive and time consuming, but causes less damage to the sample and allows the possibility to select a specific area of interest for analysis.

\subsubsection{Electron diffraction}

When an electron beam passes through a sample, the incident electrons are scattered as they interact with the crystal potential from the nuclei of the sample atoms. The diffraction pattern formed by the scattered electrons is used to study the crystal structure of solids, and it provides information on lattice constants, symmetry, crystallinity, presence of preferred orientations, defects, etc. An electron diffraction (ED) pattern can be recorded from single crystal grains if a selected area aperture is inserted into the image plane. Figure 4.6 shows ED of $(\mathrm{Cr}, \mathrm{Mn})_{2} \mathrm{GaC}$ grain in two different orientations. 

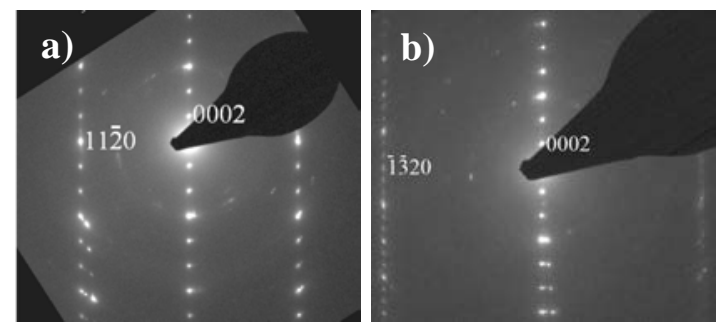

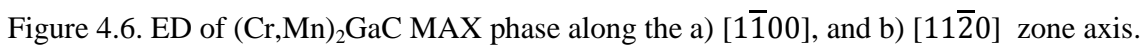

\subsubsection{Electron energy loss spectroscopy}

In electron energy loss spectroscopy (EELS), the change in the incident electron kinetic energy after inelastic interaction with the specimen is measured. Depending on the scattering atom, incident electrons experience different energy loss. To what extent depends on the atomic element, which allows mapping of the local film composition. Furthermore, the local surrounding of the atom results in fine adjustments of the characteristic energy loss, which gives information about the bonding state of the atom.

\subsubsection{Energy dispersive X-ray spectroscopy}

In energy dispersive X-ray spectroscopy (EDX), the incident electron beam excites electrons in the sample atoms to higher energy levels. De-exitation to the ground state occurs by either emission of an Auger electron (primarily for lighter elements) or an X-ray photon (primarily for heavier elements). Each element has a unique set of energies of the emitted X-rays, which allows elemental identification and mapping of the composition in a selected area of the sample.

\subsection{Vibrating sample magnetometry}

Vibrating sample magnetometry (VSM) is a technique to measure the magnetic moment of a material. A uniform magnetic field is applied, aligning the magnetic spins of a sample along the field lines. The sample is then vibrated, which induces a current in surrounding pickup coils proportional to the magnetic moment. Measurements are typically made at cryostatic temperatures to increase signal-to-noise ratio. Temperature dependent measurements are performed to obtain transition temperatures between different magnetic states. The schematic of a VSM system is given in Figure 4.7. 


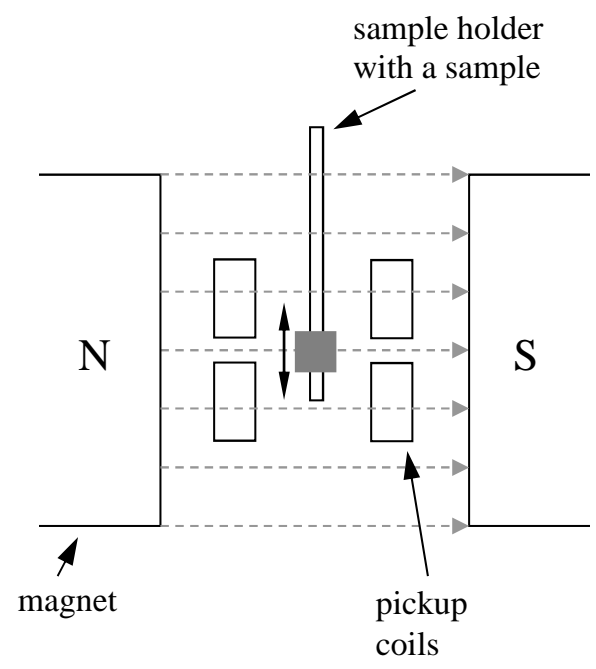

Figure 4.7. Schematic of a VSM system. 



\section{MAX phase synthesis and}

\section{characterization}

\subsection{Thin film synthesis}

The first MAX phase thin films were grown by CVD [62], however, using the PVD approach has demonstrated superior results in terms of process control and resulting crystal quality. Magnetron sputtering has so far been the most widely used technique for MAX phase depositions, employing both elemental [3, 60, 63] and compound targets [3, 64], also including reactive growth [65]. There have also been attempts to use pulsed laser deposition (PLD) and high power impulse magnetron sputtering (HiPIMS). PLD from $\mathrm{Ti}_{3} \mathrm{SiC}_{2}$ [66] and $\mathrm{Cr}_{2} \mathrm{AlC}$ [67] compound targets resulted in a deviating thin film composition with no formation of MAX phase. HiPIMS, on the other hand, resulted in nanocrystalline MAX phase together with competing phases [68, 69]. Although the applicability of PLD for MAX phase growth remains to be demonstrated and the HiPIMS approach needs to be optimized, both methods exhibit promising characteristics for controlled synthesis at reduced deposition temperatures, through energetic plasma species. Hence, these methods should be investigated further.

A comparatively new deposition method for MAX phase synthesis, compared to magnetron sputtering, is cathodic arc. Successful growth of high quality $\mathrm{Ti}_{2} \mathrm{AlC}$ films has been demonstrated by high current pulsed arc $[70,71]$ and $\mathrm{Ti}_{2} \mathrm{AlN}$ films by DC arc [72]. 
In addition, solid state reactions, either at a film/substrate or film/film interface, can be employed for MAX phase synthesis. The latter method resulted in the lowest reported formation temperature of $\mathrm{Ti}_{2} \mathrm{AlN}, 450{ }^{\circ} \mathrm{C}$, through transformation of Ti/AlN multilayers to pure $\mathrm{Ti}_{2} \mathrm{AlN}$ films [73]. A well-known example of film/substrate reaction is $\mathrm{Ti}_{3} \mathrm{SiC}_{2}$ formation at a $\mathrm{Ti} / \mathrm{SiC}$ interface, by annealing Ti-based electrodes in $\mathrm{SiC}$-based semiconductor devices [74]. Furthermore, understoichiometric $\mathrm{TiC}_{\mathrm{x}}$ deposited onto $\mathrm{Al}_{2} \mathrm{O}_{3}$ substrates at $900{ }^{\circ} \mathrm{C}$ has been reported to transform into $\mathrm{Ti}_{2} \mathrm{Al}(\mathrm{C}, \mathrm{O})$ throughout a $150 \mathrm{~nm}$ thick film, as a result of substrate decomposition followed by $\mathrm{Al}$ and $\mathrm{O}$ diffusion into $\mathrm{TiC}_{\mathrm{x}}$ [75].

\subsection{Bulk synthesis}

Bulk synthesis techniques have been the primary methods for synthesizing MAX phase materials. Two thirds of the MAX phases discovered to date are synthesized in bulk form only. A variety of methods, such as spark plasma sintering [76], pulse discharge sintering [77], combustion synthesis [78], self-propagating high-temperature synthesis [79], etc., have been explored, with emphasis on hot pressing and hot isostatic pressing [2, 80, 81]. A great advantage of MAX phases is the apparent possibility to produce fully dense MAX phase compacts without applying pressure, which enhances their potential for commercialization [82].

\subsection{Characterization of structure}

The primary structural characterization methods in this Thesis have been XRD and STEM in combination with ED.

Simple, fast and non-destructive XRD measurements were routinely used to identify constituent phases and obtain lattice constants.

A change in lattice constants may be expected upon substitution of one element by another. However, XRD $\theta-2 \theta$ measurements indicated no significant change in c-lattice parameters with composition for all here investigated MAX phase solid solutions, i.e., $(\mathrm{Cr}, \mathrm{Mn})_{2} \mathrm{AlC}$, $(\mathrm{Cr}, \mathrm{Mn})_{2} \mathrm{GeC},(\mathrm{Cr}, \mathrm{Mn})_{2} \mathrm{GaC}$, and $\mathrm{Ti}_{2} \mathrm{Al}(\mathrm{C}, \mathrm{O})$. 
It is worth noting that the experimentally obtained c-lattice parameter of the recently discovered $\mathrm{Mn}_{2} \mathrm{GaC}$ is only $0.08 \AA$ smaller than that of $\mathrm{Cr}_{2} \mathrm{GaC}, 12.55 \AA$ [17] and $12.63 \AA$ [83], respectively. For comparison, the difference in c-lattice parameter between $\mathrm{Ti}_{2} \mathrm{GaC}$ and $\mathrm{V}_{2} \mathrm{GaC}$ is $0.46 \AA$, and between $\mathrm{V}_{2} \mathrm{GaC}$ and $\mathrm{Cr}_{2} \mathrm{GaC}$ it is $0.23 \AA$. On the contrary, ab initio calculations indicate that the c-lattice parameter for $\mathrm{Mn}_{2} \mathrm{GaC}$ depends on the magnetic state, varying in the range of 12.179-12.484 $\AA$ [84]. The experimentally reported $\mathrm{c}=12.55 \AA$ is close to the calculated $\mathrm{c}=12.484 \AA$, which corresponds to an antiferromagnetic configuration.

$\mathrm{Ab}$ initio calculations predict a change in c-lattice parameter of $\mathrm{Ti}_{2} \mathrm{AlC}$ from $13.713 \AA$ to $13.665 \AA$, i.e., contraction by $0.35 \%$, upon incorporation of 12.5 at.\% O on $X$-sites [37]. Hence, no significant shifts in XRD peak positions are expected, in agreement with observations for here synthesized $\mathrm{Ti}_{2} \mathrm{Al}\left(\mathrm{C}_{0.48} \mathrm{O}_{0.52}\right)$ thin films.

The lack of peak shifts upon $\mathrm{Mn}$ incorporation into $\mathrm{Cr}_{2} A \mathrm{C}(A=\mathrm{Al}, \mathrm{Ge}, \mathrm{Ga})$ and $\mathrm{O}$ incorporation into $\mathrm{Ti}_{2} \mathrm{AlC}$ excludes XRD $\theta-2 \theta$ measurements as indicative of substitutional $\mathrm{Mn}$ and $\mathrm{O}$ in corresponding MAX phases.

During the work of this Thesis it has been discovered that MAX phase identification from symmetric XRD $\theta-2 \theta$ scans is not always straightforward. Evidence is presented that (110)-oriented epitaxial bcc $\left(\mathrm{Cr}_{1-\mathrm{y}} \mathrm{Mn}_{\mathrm{y}}\right)_{5} \mathrm{Al}_{8}$ has out-of-plane atomic spacing identical to (000n)-oriented $\left(\mathrm{Cr}_{1-\mathrm{X}} \mathrm{Mn}_{\mathrm{x}}\right)_{2} \mathrm{AlC}$. Figure 5.1 shows XRD $\theta-2 \theta$ scans of $\mathrm{Cr}_{5} \mathrm{Al}_{8}, \mathrm{Mn}_{5} \mathrm{Al}_{8}$, and a film composed both of $(\mathrm{Cr}, \mathrm{Mn})_{2} \mathrm{AlC}$ and $(\mathrm{Cr}, \mathrm{Mn})_{5} \mathrm{Al}_{8}$. Obviously, all scans look identical, which makes detection of the impurity phase challenging. Therefore, complementary analysis techniques, such as non-local composition analysis or TEM, must be performed. Methods to distinguish between $(\mathrm{Cr}, \mathrm{Mn})_{5} \mathrm{Al}_{8}$ and $(\mathrm{Cr}, \mathrm{Mn})_{2} \mathrm{AlC}$ are suggested in Paper IV. 


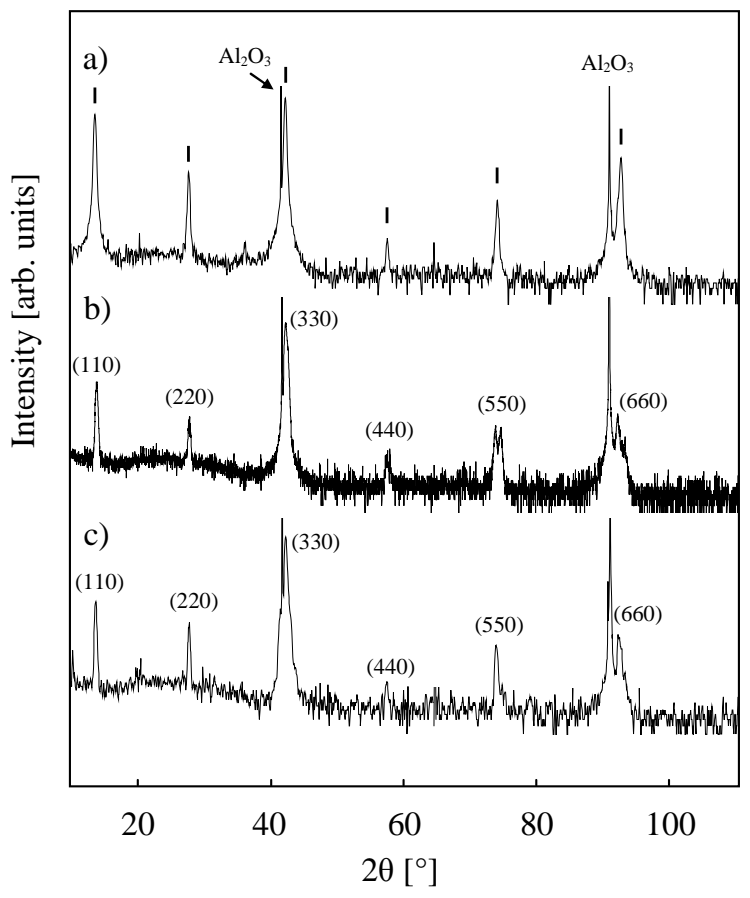

Figure 5.1. XRD $\theta-2 \theta$ scans of thin films composed of a) $\left.\left[(\mathrm{Cr}, \mathrm{Mn})_{2} \mathrm{AlC}+(\mathrm{Cr}, \mathrm{Mn})_{5} \mathrm{Al}_{8}\right], \mathrm{b}\right) \mathrm{Cr}_{5} \mathrm{Al}_{8}$, and c) $\mathrm{Mn}_{5} \mathrm{Al}_{8}$. All scans look identical.

The structure of the observed $(\mathrm{Cr}, \mathrm{Mn})_{5} \mathrm{Al}_{8}$ has been determined by ED (see Paper IV). It has been identified as bcc $(I \overline{4} 3 m)$ with a $=9.05 \AA$, forming an epitaxial relationship with the substrate $(\mathrm{Cr}, \mathrm{Mn})_{5} \mathrm{Al}_{8}(110) / / \mathrm{Al}_{2} \mathrm{O}_{3}(0001)$. The atomic spacing between (110) planes is $6.4 \AA$, which corresponds to exactly half of the c-lattice constant in $\mathrm{Cr}_{2} \mathrm{AlC}$ MAX phase. This explains the perfect peak overlap in XRD $\theta-2 \theta$ scans.

The interface between $(\mathrm{Cr}, \mathrm{Mn})_{2} \mathrm{AlC}$ and $(\mathrm{Cr}, \mathrm{Mn})_{5} \mathrm{Al}_{8}$ grains has been investigated in detail by TEM, revealing the atomic layers bridging seamlessly between the grains, despite the drastic change in composition, as shown in Figure 5.2. 


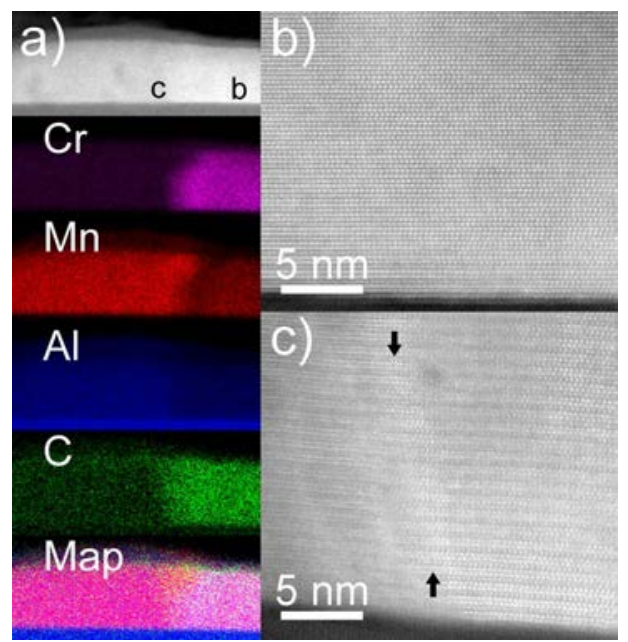

Figure 5.2. a) STEM cross-sectional image from a film composed of $\left[(\mathrm{Cr}, \mathrm{Mn})_{2} \mathrm{AlC}+(\mathrm{Cr}, \mathrm{Mn})_{5} \mathrm{Al}_{8}\right]$ with corresponding EDX elemental maps of $\mathrm{Cr}, \mathrm{Mn}, \mathrm{Al}$, and $\mathrm{C}, \mathrm{b}$ ) HRSTEM image of the $(\mathrm{Cr}, \mathrm{Mn})_{2} \mathrm{AlC}$ MAX phase structure, and c) HRSTEM image of the interface between the domains.

Other $M$ and $A$ elements that crystallize in the cubic structure identified above are $\mathrm{V}$ and $\mathrm{Al}$, forming $\mathrm{V}_{5} \mathrm{Al}_{8}$. In analogy with $(\mathrm{Cr}, \mathrm{Mn})_{2} \mathrm{AlC}$, it is therefore strongly recommended to interpret XRD $\theta-2 \theta$ scans of $\mathrm{V}_{2} \mathrm{AlC}$ with care, and use complementary techniques for phase identification.

TEM and HRTEM structural analysis of MAX phases has been performed for different resolution. Large (>>100 nm) grains of high crystal quality were identified in a $1 \mu \mathrm{m}$ thick $(\mathrm{Cr}, \mathrm{Mn})_{2} \mathrm{AlC}$ thin film, and a $36 \mathrm{~nm}(\mathrm{Cr}, \mathrm{Mn})_{2} \mathrm{GeC}$ thin film has been revealed as single crystal material. Figure 5.3 shows an aberration corrected STEM images of $(\mathrm{Cr}, \mathrm{Mn})_{2} \mathrm{AlC}$ MAX phase, demonstrating superior structural quality.

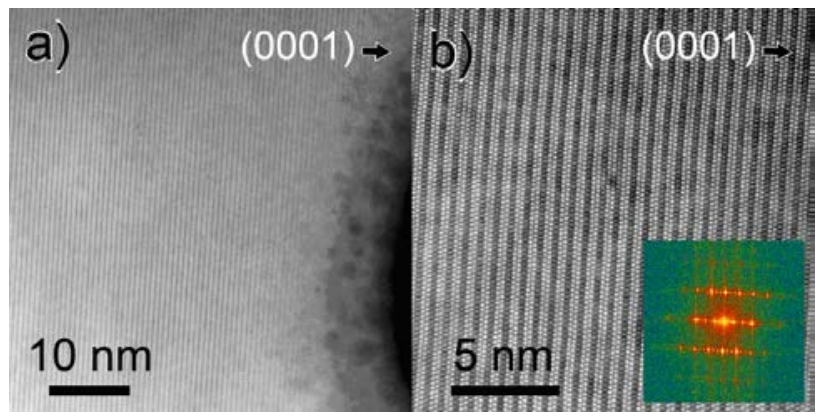

Figure 5.3. a) Lattice resolved, and b) high resolution aberration corrected STEM images of the $(\mathrm{Cr}, \mathrm{Mn})_{2} \mathrm{AlC}$ film revealing superior crystal quality. 


\subsection{Characterization of composition}

Quantification of the constituting elements in the MAX phase has been an important aspect in this Thesis work, as the precise concentration of Mn and $\mathrm{O}$ in the MAX phase structure had to be obtained. In non-local analysis techniques, the determined composition is affected by, e.g., possible atom agglomeration along grain boundaries, or by presence of competing phases. Therefore, the non-local analysis techniques have been used for primary analysis only.

SEM-EDX has been employed for initial evaluation of elemental $M: A$ and $\mathrm{Cr}: \mathrm{Mn}$ ratios during synthesis optimization. Considerable deviations from the stoichiometric $M: A$ ratio, which is 2:1 for here investigated MAX phases, indicate presence of impurities. For example, considerably lower concentration of $M$ element $(M: A=1: 1)$ has been detected in a sample where later TEM analysis revealed formation of $(\mathrm{Cr}, \mathrm{Mn})_{5} \mathrm{Al}_{8}$ in addition to $(\mathrm{Cr}, \mathrm{Mn})_{2} \mathrm{AlC}$. It should be noted that for $A=\mathrm{Al}$, MAX phase thin films intended for SEM-EDX analysis should be deposited on other substrates than $\mathrm{Al}_{2} \mathrm{O}_{3}$. If not, the films must be of thickness $>1 \mu \mathrm{m}$, as in the first experiments on $\mathrm{Mn}$ incorporation into $\mathrm{Cr}_{2} \mathrm{AlC}$ in this Thesis.

Although using a non-local composition analysis technique for selected thin films, SEM-EDX analysis was estimated to provide local composition in bulk samples, as point measurements were performed on large well defined MAX phase grains.

In order to obtain local quantification with respect to composition for thin films, TEM equipped with EDX and/or EELS has been used, and measurements have been performed on high crystal quality MAX phase grains. STEM elemental maps were acquired to investigate the homogeneity of $\mathrm{Mn}$ incorporation in $(\mathrm{Cr}, \mathrm{Mn})_{2} \mathrm{AlC}$ and $(\mathrm{Cr}, \mathrm{Mn})_{2} \mathrm{GeC}$. No variations in composition within the same grain or in between different grains in the same sample were detected.

Theoretical calculations indicate that stability and magnetic properties of $(\mathrm{Cr}, \mathrm{Mn})_{2} \mathrm{AlC}$ and (Cr, Mn $)_{2} \mathrm{GeC}$ potentially depend on Cr-Mn distribution on the $M$-sublattice. Disordered solid solutions as well as formation of pure $\mathrm{Cr}$ and $\mathrm{Mn}$ layers have been considered $[14,15]$. In order to investigate the $\mathrm{Cr}-\mathrm{Mn}$ distribution, lattice resolved EDX elemental maps were obtained for $(\mathrm{Cr}, \mathrm{Mn})_{2} \mathrm{GeC}$. In Figure 5.4 the separation between $M$ and $A$ layers is clearly visible. $\mathrm{Cr}$ and $\mathrm{Mn}$ intermixing is revealed, indicating a random solid solution, as could be expected from co-sputtering at elevated temperatures. 

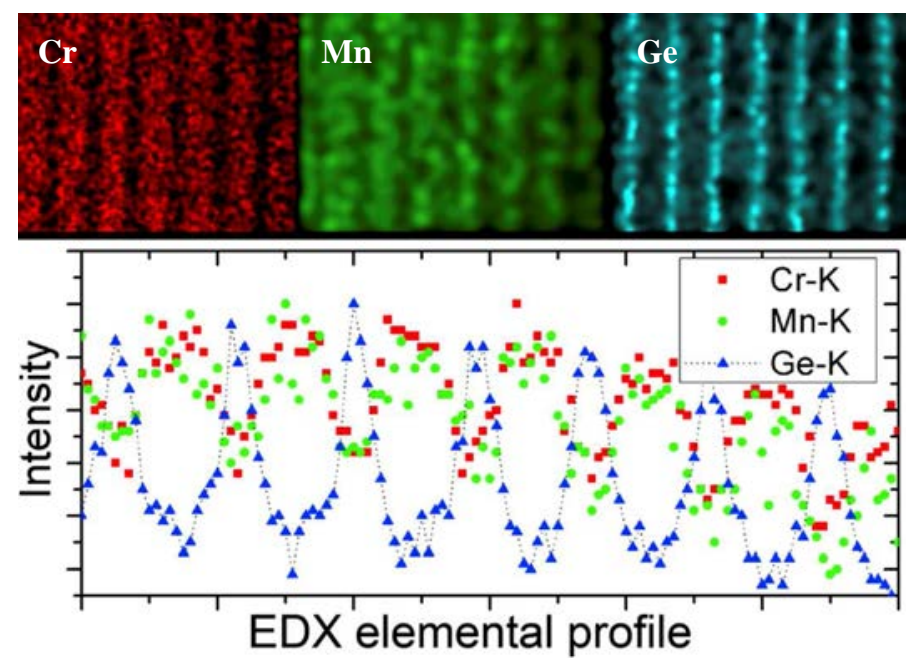

Figure 5.4. Lattice resolved EDX elemental mapping and an averaged EDX line profile of $(\mathrm{Cr}, \mathrm{Mn})_{2} \mathrm{GeC}$ showing clearly separated $M$ and $A$ layers. $\mathrm{Cr}$ and $\mathrm{Mn}$ intermixing is revealed, indicating a random solid solution.

Lattice resolved EDX mapping has also been attempted for $(\mathrm{Cr}, \mathrm{Mn})_{2} \mathrm{AlC}$, however, the structure disintegrated under the exposure of the focused electron beam.

For accurate composition determination, EDX and EELS have frequently been combined as complementary methods. The $M: A$ ratio has sometimes been used as indicative for MAX phase composition, since $\mathrm{C}$ is generally difficult to quantify. As a light element, it cannot be quantified accurately in EDX, while in an EELS spectrum the $\mathrm{C}$ edge is very close to the zero-loss peak. Special attention has been directed towards determination of precise $\mathrm{Cr}$ and

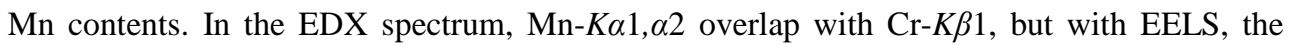
$\mathrm{Cr}-L 2,3$ and $\mathrm{Mn}-L 2,3$ edges are separated.

$\mathrm{Mn}$ incorporation of 10 at.\% has been attained in $(\mathrm{Cr}, \mathrm{Mn})_{2} \mathrm{AlC}$, and 12.5 at.\% in $(\mathrm{Cr}, \mathrm{Mn})_{2} \mathrm{GeC}$ thin films. This corresponds to every fifth and fourth $\mathrm{Cr}$ atom, respectively, being replaced with $\mathrm{Mn}$. Theoretical calculations predict incorporation of at least 30 at.\% $\mathrm{Mn}$ into $(\mathrm{Cr}, \mathrm{Mn})_{2} \mathrm{AlC}[15]$ and $\sim 10-15$ at.\% in $(\mathrm{Cr}, \mathrm{Mn})_{2} \mathrm{GeC}$ [14]. For the corresponding $A=\mathrm{Ga}$ MAX phase, $(\mathrm{Cr}, \mathrm{Mn})_{2} \mathrm{GaC}$, stability throughout the whole composition range can be expected, as $\mathrm{Mn}_{2} \mathrm{GaC}$ has been theoretically predicted and experimentally confirmed by the synthesis of phase pure $\mathrm{Mn}_{2} \mathrm{GaC}$ thin films very recently [17]. In this Thesis, $(\mathrm{Cr}, \mathrm{Mn})_{2} \mathrm{GaC}$ was investigated in bulk form, with an attained Mn content of 15 at.\%. The differences between levels of Mn incorporation in the thin films vs. the bulk samples can be explained by the synthesis conditions. In contrast to bulk synthesis, thin film growth is performed far from thermodynamic equilibrium, which can result in enhanced solubility limits. Moreover, the 
formation of MAX phases in thin film deposition can be promoted, over competing phases, by the choice of substrate - most often $\mathrm{Al}_{2} \mathrm{O}_{3}(0001)$ or $\mathrm{MgO}(111)$ - providing a template corresponding to the MAX phase a-lattice spacing.

Concentration of 13 at.\% of $\mathrm{O}$ in $\mathrm{Ti}_{2} \mathrm{Al}\left(\mathrm{C}_{1-\mathrm{x}} \mathrm{O}_{\mathrm{x}}\right)$ has been determined, with resultant composition of $\operatorname{Ti}_{2} \mathrm{Al}\left(\mathrm{C}_{0.48} \mathrm{O}_{0.52}\right)$. This is in excellent agreement with theory, where $\mathrm{O}$ solubility limit of $x \approx 0.5$ is predicted [37]. 


\section{Summary of the included}

\section{papers}

\subsection{Paper I}

\section{Synthesis and ab initio calculations of nanolaminated $(\mathrm{Cr}, \mathrm{Mn})_{2} \mathrm{AlC}$ compounds}

In this paper, theoretical predictions and experimental observations of the first Mn containing MAX phase are reported.

Temperature dependent stability of $\left(\mathrm{Cr}_{1-\mathrm{x}} \mathrm{Mn}_{\mathrm{x}}\right)_{2} \mathrm{AlC}$ with $0.0 \leq \mathrm{x} \leq 0.5$ has been theoretically investigated assuming a random $\mathrm{Cr}-\mathrm{Mn}$ intermixing on the $M$-site. The results indicate 211 MAX phase stability over the considered composition range for temperatures $\geq 600 \mathrm{~K}$.

The $\left(\mathrm{Cr}_{1-\mathrm{x}} \mathrm{Mn}_{\mathrm{x}}\right)_{2} \mathrm{AlC}$ thin films were deposited on $\mathrm{Al}_{2} \mathrm{O}_{3}(0001)$ substrates by magnetron sputtering from four elemental targets. XRD phase analysis shows that the films predominantly consist of epitaxially oriented 211 MAX phase. Calculations of the change in lattice parameters upon addition of $\mathrm{Mn}$ have been performed, indicating a slight linear decrease in the c-axis and no significant change of the a-axis. However, the predicted XRD peak shift with respect to pure $\mathrm{Cr}_{2} \mathrm{AlC}$ is too small to allow quantification of the $\mathrm{Mn}$ concentration. 
Analytical TEM including EELS and EDX has been used in scanning mode for elemental mapping in MAX phase areas of high structural quality. A $\mathrm{Cr} / \mathrm{Mn}$ based MAX phase alloy was revealed, including a Mn concentration of 8 at.\%.

Inspired by previous theoretical work on $\left(\mathrm{Cr}_{1-\mathrm{x}} \mathrm{Mn}_{\mathrm{x}}\right)_{2} \mathrm{AlC}$ predicting tunability of the magnetic state by $M$ element configuration [15], this material is highly promising for further investigations with respect to magnetic properties.

\subsection{Paper II}

\section{Magnetic self-organized atomic laminate from first principles and thin film synthesis}

In this paper, a new family of inherently nanolaminated magnetic materials is uncovered. Phase stability and magnetic properties of $M_{n+l} \mathrm{GeC}_{n}(\mathrm{M}=\mathrm{Ti}, \mathrm{V}, \mathrm{Cr}$, and $\mathrm{Mn})$ have been investigated from first principles and $\left(\mathrm{Cr}_{1-\mathrm{x}} \mathrm{Mn}_{\mathrm{x}}\right)_{2} \mathrm{GeC}$ was identified as a stable magnetic MAX phase alloy. Several configurations of $\mathrm{Cr}$ and $\mathrm{Mn}$ atoms on the $M$-sublattice were considered, in different magnetic states for $x=0.25$ and $x=0.50$.

$\left(\mathrm{Cr}_{1-\mathrm{x}} \mathrm{Mn}_{\mathrm{x}}\right)_{2} \mathrm{GeC}$ thin films have been deposited on $\mathrm{MgO}(111)$ substrates by magnetron sputtering. XRD $\theta-2 \theta$ analysis shows high quality epitaxial MAX phase structure. Elemental mapping from STEM equipped with EDX reveals a Mn concentration of 12.5 at.\%.

The magnetic properties in the temperature range of 50-300 $\mathrm{K}$ have been evaluated by VSM, displaying ferromagnetic response up to $200 \mathrm{~K}$, although the thin film is magnetic also at room temperature. The saturation moment of $0.36 \mu_{\mathrm{B}}$ per $\mathrm{Mn}$ atom at $50 \mathrm{~K}$ has been experimentally determined, which is a factor of 6 smaller than predicted theoretically. This may be due to a combination of ferro- and antiferromagnetic coupling.

New magnetic nanolaminates are vital for an increased stability, scalability, and efficiency in, for example, sensor and information technology components. Magnetic MAX phases unveil a new research area, with potential for future applications. 


\subsection{Paper III}

\section{Synthesis and characterization of arc deposited $(\mathrm{Cr}, \mathrm{Mn})_{2} \mathrm{AIC}$ MAX phase films}

The results presented in this paper add $(\mathrm{Cr}, \mathrm{Mn})_{2} \mathrm{AlC}$ to the recently discovered group of magnetic MAX phases.

Thin films of $\left(\mathrm{Cr}_{1-\mathrm{x}} \mathrm{Mn}_{\mathrm{x}}\right)_{2} \mathrm{AlC}$ have been deposited on $\mathrm{Al}_{2} \mathrm{O}_{3}(0001)$ substrates by high current pulsed cathodic arc. The composition has been determined by STEM equipped with EDX. The highest Mn content obtained to date has been realized, with 10 at.\% in here synthesized samples, corresponding to $\left(\mathrm{Cr}_{0.8} \mathrm{Mn}_{0.2}\right)_{2} \mathrm{AlC}$.

No previous $\left(\mathrm{Cr}_{1-\mathrm{x}} \mathrm{Mn}_{\mathrm{x}}\right)_{2} \mathrm{AlC}$ MAX phase has been characterized with respect to magnetic properties. Therefore, magnetic response in the temperature range of 5-280 $\mathrm{K}$ has been measured by VSM. No hysteresis was observed, which may be explained by the non-uniform island structure of the film, or degeneracy between antiferromagnetic and ferromagnetic configurations, consistent with theoretical predictions. The saturation magnetic moment per $M$ atom is $>0.16 \mu_{\mathrm{B}}$ at $10 \mathrm{~K}$, and its weak dependence on temperature indicates that the magnetic transition temperature is considerably higher than $280 \mathrm{~K}$. These results are highly promising, as a high magnetic transition temperature is a generally required property for functionalization of magnetic phases.

\subsection{Paper IV}

\section{Structural and magnetic properties of $\left(\mathrm{Cr}_{1-\mathrm{x}} \mathrm{Mn}_{\mathrm{x}}\right)_{5} \mathrm{Al}_{8}$ solid solution and structural relation to hexagonal nanolaminates}

In this paper it is shown that for $(\mathrm{Cr}, \mathrm{Mn})_{2} \mathrm{AlC}$ thin films, phase analysis cannot be based on XRD $\theta-2 \theta$ measurements only. Evidence is presented of formation of (ll0)-oriented bcc $\left(\mathrm{Cr}_{1-\mathrm{x}} \mathrm{Mn}_{\mathrm{x}}\right)_{5} \mathrm{Al}_{8}$ during synthesis of $(000 \mathrm{n})$-oriented $(\mathrm{Cr}, \mathrm{Mn})_{2} \mathrm{AlC}$, both phases resulting in identical $\theta-2 \theta$ scans with respect to the peak positions.

After attempted arc synthesis of $(\mathrm{Cr}, \mathrm{Mn})_{2} \mathrm{AlC}$, phase identification through XRD $\theta-2 \theta$ measurements indicated close to phase pure films. However, from HRTEM, grains of an unknown phase could be observed, exhibiting a layered structure similar to a MAX phase, though with no C. In order to investigate the structure of this phase, ED and XRD pole measurements were performed on synthesized reference samples containing this phase only. 
The structure was identified as bcc with a $=9.05 \AA$, growing with (110) planes parallel to the substrate. In combination with the composition analysis, the phase could be identified as $(\mathrm{Cr}, \mathrm{Mn})_{5} \mathrm{Al}_{8}$.

Further HRSTEM investigations revealed that an interlayer spacing between (110) planes in $(\mathrm{Cr}, \mathrm{Mn})_{5} \mathrm{Al}_{8}$ is equal to half of the c-lattice parameter of $(\mathrm{Cr}, \mathrm{Mn})_{2} \mathrm{AlC}$, i.e., $6.4 \AA$. The atomic layers bridge seamlessly between $(\mathrm{Cr}, \mathrm{Mn})_{2} \mathrm{AlC}$ and $(\mathrm{Cr}, \mathrm{Mn})_{5} \mathrm{Al}_{8}$ grains, despite the drastic change in composition. XRD pole measurements at $2 \theta=42.3^{\circ}$ are suggested for detection of $(\mathrm{Cr}, \mathrm{Mn})_{5} \mathrm{Al}_{8}$, through the presence of six-fold symmetric peaks at $33.5^{\circ}, 60^{\circ}$, and $70.3^{\circ}$, corresponding to angles between (110) and (411) planes in bcc crystal structure.

$(\mathrm{Cr}, \mathrm{Mn})_{2} \mathrm{AlC} \mathrm{MAX}$ phase has recently been predicted to exhibit magnetic properties. Therefore, VSM characterization of $(\mathrm{Cr}, \mathrm{Mn})_{5} \mathrm{Al}_{8}$ and $\mathrm{Mn}_{5} \mathrm{Al}_{8}$ films was performed, revealing that they are both magnetic, and with a magnetic moment of $0.16 \mu_{\mathrm{B}}$ per $M$ atom at $10 \mathrm{~K}$ in $\left(\mathrm{Cr}_{0.28} \mathrm{Mn}_{0.72}\right)_{5} \mathrm{Al}_{8}$. This should be kept in mind when evaluating the magnetic properties of a MAX phase sample.

In conclusion, XRD $\theta-2 \theta$ measurements of $(\mathrm{Cr}, \mathrm{Mn})_{2} \mathrm{AlC}$ thin films must always be complemented with analysis techniques resolving both structure and composition for unambiguous phase identification.

\subsection{Paper V}

\section{Solid solubility and magnetism upon $\mathrm{Mn}$ incorporation in bulk $\mathrm{Cr}_{2} \mathrm{AlC}$ and $\mathrm{Cr}_{2} \mathrm{GaC}$ MAX phases}

In this paper, the solubility of $\mathrm{Mn}$ in bulk $\mathrm{Cr}_{2} \mathrm{AlC}$ and $\mathrm{C}_{2} \mathrm{GaC}$ has been investigated. The $\left(\mathrm{Cr}_{1-\mathrm{x}} \mathrm{Mn}_{\mathrm{x}}\right)_{2} \mathrm{AlC}$ and $\left(\mathrm{Cr}_{1-\mathrm{y}} \mathrm{Mn}_{\mathrm{y}}\right)_{2} \mathrm{GaC}$ samples were synthesized by heat treating elemental powder mixtures at $1400{ }^{\circ} \mathrm{C}$ for $1 \mathrm{~h}$ under Ar flow, and at $975{ }^{\circ} \mathrm{C}$ for $24 \mathrm{~h}$ in mechanical vacuum, respectively. Mn incorporation of 3 and 15 at.\% was determined, resulting in compositions of $\left(\mathrm{Cr}_{0.94} \mathrm{Mn}_{0.06}\right)_{2} \mathrm{AlC}$ and $\left(\mathrm{Cr}_{0.7} \mathrm{Mn}_{0.3}\right)_{2} \mathrm{GaC}$. The latter corresponds to about one third of the $M$-lattice sites being occupied by $\mathrm{Mn}$ atoms. The lower $\mathrm{Mn}$ content in the here produced bulk MAX phase samples compared to the reported thin film counterparts may be explained by thin film growth being performed far from thermodynamic equilibrium, which can result in enhanced solubility limits. Moreover, the formation of MAX phases in thin film deposition can be promoted, over competing phases, by epitaxial stabilization from the 
substrate. XRD analysis showed that introduction of Mn into the MAX phase structure did not result in any significant change in the c-lattice parameter.

VSM measurements were performed for initial magnetic characterization. $\left(\mathrm{Cr}_{0.94} \mathrm{Mn}_{0.06}\right)_{2} \mathrm{AlC}$ showed no magnetic response, which is not surprising at such low $\mathrm{Mn}$ content. For $\left(\mathrm{Cr}_{0.7} \mathrm{Mn}_{0.3}\right)_{2} \mathrm{GaC}$, on the other hand, magnetic transitions were observed at 38 and $153 \mathrm{~K}$, suggesting that the phase may be magnetic.

\subsection{Paper VI}

\section{Oxygen incorporation in $\mathrm{Ti}_{2} \mathrm{AlC}$ thin films studied by electron energy loss spectroscopy and ab initio calculations}

The $\mathrm{O}$ content in $\mathrm{Ti}_{2} \mathrm{AlC}$ thin film samples has previously been measured by elastic recoil detection analysis (ERDA) (20 at.\%) [75] and roughly estimated by EELS (5-10 at.\%, depending on the choice of the model) [38]. Even though previous theoretical as well as experimental results indicate that $\mathrm{O}$ substitutes for $\mathrm{C}$ in the MAX phase, the ERDA results must be interpreted with care, as they may also include $\mathrm{O}$ contribution from grain boundaries and other structural imperfections acting as $\mathrm{O}$ getters. In this Thesis, unambiguous measurements on the $\mathrm{O}$ content in the $\mathrm{Ti}_{2} \mathrm{AlC}$ MAX phase structure have been performed, employing reference-based EELS.

The range of $\mathrm{O}$ concentration attained in MAX phase oxycarbide $\mathrm{Ti}_{2} \mathrm{Al}\left(\mathrm{C}_{1-\mathrm{x}} \mathrm{O}_{\mathrm{x}}\right)$ was explored using two thin film synthesis routes: deposition of $\mathrm{Ti}_{2} \mathrm{AlC}_{\mathrm{y}}$ by pulsed cathodic arc under high vacuum conditions, and solid-state reactions following deposition of understoichiometric $\mathrm{TiC}_{\mathrm{z}}$ on $\mathrm{Al}_{2} \mathrm{O}_{3}$. An $\mathrm{O}$ concentration of $10-13$ at.\% was measured. Furthermore, calculations were performed to investigate the effect of substitutional $\mathrm{O}$ on the shearing behavior. A linear increase in the ideal strength for $[\overline{1} 010](0001)$ and $[1 \overline{2} 10](0001)$ shear paths was found for an increased $\mathrm{O}$ content.

The obtained $\mathrm{O}$ concentration range is wide enough to allow experimental investigations of the previously suggested (from theory) change in anisotropic conductivity with increasing $\mathrm{O}$ content [12], as well as to measure any accompanying change in the bulk modulus. Altogether, the results show an $\mathrm{O}$ concentration range potentially allowing tuning of the material's electronic and mechanical properties. 



\section{Contribution to the field}

The research presented in this Thesis is focused on adding new properties to MAX phases by exploring incorporation of new elements. I have performed materials synthesis by both thin film and bulk methods and have been particularly interested in realization of magnetic MAX phases.

I hope that my work will provide the basis for future research and further advancements in the recently established research area of magnetic MAX phases.

My main contributions are as follows:

In general terms,

- I have realized the first materials based on Mn as an $M$ element in MAX phases, more specifically, $(\mathrm{Cr}, \mathrm{Mn})_{2} \mathrm{AlC},(\mathrm{Cr}, \mathrm{Mn})_{2} \mathrm{GeC}$, and $(\mathrm{Cr}, \mathrm{Mn})_{2} \mathrm{GaC}$.

- I have showed that both thin film synthesis (cathodic arc and magnetron sputtering) as well as bulk synthesis (pressureless sintering and hot pressing) methods are viable approaches for Mn incorporation into the MAX phase.

- I have shown that solubility of $\mathrm{Mn}$ in $(\mathrm{Cr}, \mathrm{Mn})_{2} \mathrm{AlC}$ is higher for thin films as compared to bulk.

- I have reported the first experimental evidence of magnetic MAX phases, namely $(\mathrm{Cr}, \mathrm{Mn})_{2} \mathrm{AlC},(\mathrm{Cr}, \mathrm{Mn})_{2} \mathrm{GeC}$, and $(\mathrm{Cr}, \mathrm{Mn})_{2} \mathrm{GaC}$. 
- I have presented evidence for (1l0)-oriented epitaxial $(\mathrm{Cr}, \mathrm{Mn})_{5} \mathrm{Al}_{8}$ resulting in $\mathrm{XRD}$ $\theta-2 \theta$ scans identical to $(000 \mathrm{n})$-oriented $(\mathrm{Cr}, \mathrm{Mn})_{2} \mathrm{AlC}$, which challenges correct phase identification.

- I have investigated incorporation of $\mathrm{O}$ as $X$ element in $\mathrm{Ti}_{2} \mathrm{AlC}$, where $\mathrm{O}$ originates from residual gas and $\mathrm{Al}_{2} \mathrm{O}_{3}$ substrate decomposition.

More specifically,

- I have incorporated 10 and 12.5 at.\% of $\mathrm{Mn}$ into $\mathrm{Cr}_{2} \mathrm{AlC}$ and $\mathrm{Cr}_{2} \mathrm{GeC}$ thin films, respectively, with resultant compositions of $\left(\mathrm{Cr}_{0.8} \mathrm{Mn}_{0.2}\right)_{2} \mathrm{AlC}$ and $\left(\mathrm{Cr}_{0.75} \mathrm{Mn}_{0.25}\right)_{2} \mathrm{GeC}$.

- I have incorporated 3 and 15 at.\% of $\mathrm{Mn}$ into bulk $\mathrm{Cr}_{2} \mathrm{AlC}$ and $\mathrm{Cr}_{2} \mathrm{GaC}$, respectively, with resultant compositions of $\left(\mathrm{Cr}_{0.94} \mathrm{Mn}_{0.06}\right)_{2} \mathrm{AlC}$ and $\left(\mathrm{Cr}_{0.7} \mathrm{Mn}_{0.3}\right)_{2} \mathrm{GaC}$, showing lower Mn solubility compared to thin films.

- I have concluded magnetic response of $(\mathrm{Cr}, \mathrm{Mn})_{2} \mathrm{AlC}$ above room temperature.

- I have shown ferromagnetic response of $(\mathrm{Cr}, \mathrm{Mn})_{2} \mathrm{GeC}$.

- I have suggested specific pole figure measurements for unambiguous differentiation between epitaxial $(\mathrm{Cr}, \mathrm{Mn})_{5} \mathrm{Al}_{8}$ and $(\mathrm{Cr}, \mathrm{Mn})_{2} \mathrm{AlC}$ phases in thin films.

- I have shown an $\mathrm{O}$ content of 13 at. $\%$ in $\mathrm{Ti}_{2} \mathrm{Al}(\mathrm{C}, \mathrm{O})$, with resultant composition of $\mathrm{Ti}_{2} \mathrm{Al}\left(\mathrm{C}_{0.48} \mathrm{O}_{0.52}\right)$. This corresponds to half of the $\mathrm{C}$ atoms substituted by $\mathrm{O}$, in agreement with a theoretically suggested $\mathrm{O}$ solubility limit. 


\section{Future outlook}

My research has resulted in the first experimental verification of magnetic MAX phases. The research area is therefore new, with a lot of challenging and exciting experiments awaiting. Here I would like to lay out a few selected directions for future investigations.

- An increase in the magnetic moment is predicted for an increased Mn concentration. Therefore, further enhancement of the Mn content in the MAX phase should be attempted.

- Theoretical calculations predict that the magnetic state depends on Cr-Mn distribution on the $M$-sublattice, e.g., formation of pure $\mathrm{Cr}$ and $\mathrm{Mn}$ layers. Attempts to synthesize such ordered MAX phase alloys are encouraged.

- A series of samples with different Mn concentrations should be experimentally investigated in order to demonstrate the possibility to tune the magnetic properties, and determine if a threshold Mn content exists. Also, detailed studies investigating magnetic properties and their dependence on lattice site should ideally be performed by, e.g., neutron diffraction.

- Exchange correlation is often enhanced in nitrides, as compared to corresponding carbides, which motivates studies also on potentially magnetic $(\mathrm{Cr}, \mathrm{Mn})_{2} \mathrm{GaN} \mathrm{MAX}$ phase. 
- Removal of the $A$ layer in selected MAX phases has resulted in a family of 2D nanocrystals denoted MXenes. It would be intriguing to form magnetic MXene, and explore the magnetic properties upon a reduced dimensionality. 


\section{References}

[1] H. Nowotny, Strukturchemie einiger Verbindungen der Ubergangsmetalle mit den Elementen C, Si, Ge, Sn, Prog. Solid State Chem. 2 27-62 (1970).

[2] M.W. Barsoum and T. El-Raghy, Synthesis and characterization of a remarkable ceramic: $\mathrm{Ti}_{3} \mathrm{SiC}_{2}$, J. Am. Ceram. Soc. 79(7) 1953-1956 (1996).

[3] J.-P. Palmquist, U. Jansson, T. Seppänen, P.O.Å. Persson, J. Birch, L. Hultman, and P. Isberg, Magnetron sputtered epitaxial single-phase $\mathrm{Ti}_{3} \mathrm{SiC}_{2}$ thin films, Appl. Phys. Lett. 81(5) 835-837 (2002).

[4] M. Naguib, M. Kurtoglu, V. Presser, J. Lu, J. Niu, M. Heon, L. Hultman, Y. Gogotsi, and M.W. Barsoum, Two-dimensional nanocrystals produced by exfoliation of $\mathrm{Ti}_{3} A l C_{2}$, Adv. Mater. XX 1-6 (2011).

[5] M. Naguib, O. Mashtalir, J. Carle, V. Presser, J. Lu, L. Hultman, Y. Gogotsi, and M.W. Barsoum, Two-dimensional transition metal carbides, ACS Nano 6(2) 13221331 (2012).

[6] M. Naguib, J. Come, B. Dyatkin, V. Presser, P.-L. Taberna, P. Simon, M.W. Barsoum, and Y. Gogotsi, MXene: a promising transition metal carbide anode for lithium-ion batteries, Electrochem. Commun. 16 61-64 (2012).

[7] A.N. Enyashin and A.L. Ivanovskii, Prediction of atomic structure and electronic properties of $\mathrm{Ti}_{3} \mathrm{SiC}_{2}$ based nanotubes by DFTB theory, Mater. Lett. 62 663-665 (2008).

[8] R. Grieseler, B. Hähnlein, M. Stubenrauch, T. Kups, M. Wilke, M. Hopfeld, J. Pezoldt, and P. Schaaf, Nanostructured plasma etched, magnetron sputtered nanolaminar $\mathrm{Cr}_{2} \mathrm{AlC}$ MAX phase thin films, Appl. Surf. Sci. 292 997-1001 (2014). 
[9] A. Mendoza-Galvan, M. Rybka, K. Jarrendahl, H. Arwin, M. Magnusson, L. Hultman, and M.W. Barsoum, Spectroscopic ellipsometry study on the dielectric function of bulk Ti $i_{2} \mathrm{AlN}, \quad \mathrm{Ti} i_{2} \mathrm{AlC}, \quad \mathrm{Nb}_{2} \mathrm{AlC}, \quad\left(\mathrm{Ti}_{0.5}, \mathrm{Nb}_{0.5}\right)_{2} \mathrm{AlC}$, and $\mathrm{Ti}_{3} \mathrm{Ge} \mathrm{C}_{2} \mathrm{MAX}$-phases, J. Appl. Phys. 109013530 (2011).

[10] C. Li, Z. Wang, and C. Wang, Effects of aluminium vacancies on electronic structure and optical properties of $\mathrm{Ta}_{4} \mathrm{AlC} \mathrm{C}_{3}$ : A first principles study, Physica B Condens. Matter. 406(20) 3906-3910 (2011).

[11] N. Haddad, E. Garcia-Caurel, L. Hultman, M.W. Barsoum, and G. Hug, Dielectric properties of $\mathrm{Ti}_{2} \mathrm{AlC}$ and $\mathrm{Ti}_{2} \mathrm{AlN}$ MAX phases: The conductivity anisotropy, J. Appl. Phys. 104023531 (2008).

[12] J. Rosen, M. Dahlqvist, S.I. Simak, D.R. McKenzie, and M.M.M. Bilek, Oxygen incorporation in $\mathrm{Ti}_{2} \mathrm{AlC}$ : Tuning of anisotropic conductivity, Appl. Phys. Lett. 97 073103 (2010).

[13] V. Mauchamp, W. Yu, L. Gence, L. Piraux, T. Cabioc'h, V. Gauthier, P. Eklund, and $\mathrm{S}$. Dubois, Anisotropy of the resistivity and charge-carrier sign in nanolaminated $\mathrm{Ti}_{2} \mathrm{AlC}$ : Experiment and ab initio calculations, Phys. Rev. B 87235105 (2013).

[14] A.S. Ingason, A. Mockute, M. Dahlqvist, F. Magnus, S. Olafsson, U.B. Arnalds, B. Alling, I.A. Abrikosov, B. Hjorvarsson, P.O.A. Persson, and J. Rosen, Magnetic self-organized atomic laminate from first principles and thin film synthesis, Phys. Rev. Lett. 110195502 (2013).

[15] M. Dahlqvist, B. Alling, I.A. Abrikosov, and J. Rosen, Magnetic nanoscale laminates with tunable exchange coupling from first principles, Phys. Rev. B 84(22) 220403 (2011).

[16] W. Luo and R. Ahuja, Magnetic $\mathrm{Fe}_{n+1} A C_{n}(n=1,2,3$, and $A=A l$, Si, Ge) phases: from ab initio theory, J. Phys.: Condens. Matter. 20064217 (2008).

[17] A.S. Ingason, A. Petruhins, M. Dahlqvist, F. Magnus, A. Mockute, B. Alling, L. Hultman, I.A. Abrikosov, P.O.Å. Persson, and J. Rosen, A nanolaminated magnetic phase: $\mathrm{Mn}_{2} \mathrm{GaC}$, Mater. Res. Lett. 2(2) 89-93 (2013).

[18] S. Lin, P. Tong, B.S. Wang, Y.N. Huang, W.J. Lu, D.F. Shao, B.C. Zhao, W.H. Song, and Y.P. Sun, Magnetic and electric/thermal transport properties of Mn-doped $M_{n+1} A X_{n}$ phase compounds $\mathrm{Cr}_{2-x} M n_{x} G a C(O \leq x \leq 1)$, J. Appl. Phys. 113053502 (2013).

[19] A. Mockute, J. Lu, E.J. Moon, M. Yan, B. Anasori, S.J. May, M.W. Barsoum, and J. Rosen, Solid solubility and magnetism upon Mn incorporation in bulk $\mathrm{Cr}_{2} \mathrm{AlC}$ and $\mathrm{Cr}_{2} \mathrm{GaC} M A X$ phases, in manuscript.

[20] P. Eklund, M. Beckers, U. Jansson, H. Högberg, and L. Hultman, The $M_{n+1} A X_{n}$ phases: Materials science and thin-film processing, Thin Solid Films 518(8) 18511878 (2010). 
[21] L. Zheng, J. Wang, X. Lu, F. Li, J. Wang, and Y. Zhou, $\left(T_{0.5} \mathrm{Nb}_{0.5}\right)_{5} A l C_{4}:$ A newlayered compound belonging to MAX phases, J. Am. Ceram. Soc. 93(10) 3068-3071 (2010).

[22] Z. Lin, M. Zhuo, Y. Zhou, M. Li, and J. Wang, Microstructures and theoretical bulk modulus of layered ternary tantalum aluminum carbides, J. Am. Ceram. Soc. 89(12) 3765-3769 (2006).

[23] J. Zhang, B. Liu, J.Y. Wang, and Y.C. Zhou, Low-temperature instability of $T i_{2} S n C$ : A combined transmission electron microscopy, differential scanning calorimetry, and $X$-ray diffraction investigations, J. Mater. Res. 24 39-49 (2009).

[24] M.W. Barsoum, The $M_{N+1} A X_{N}$ phases: A new class of solids, Prog. Solid State Chem. 28 201-281 (2000).

[25] M.W. Barsoum, H.I. Yoo, I.K. Polushina, V.Y. Rud, Y.V. Rud, and T. El-Raghy, Electrical conductivity, thermopower, and Hall effect of $\mathrm{Ti}_{3} \mathrm{AlC}_{2}, \mathrm{Ti}_{4} \mathrm{AlN}_{3}$, and $\mathrm{Ti}_{3} \mathrm{SiC}_{2}$, Phys. Rev. B 62(15) 10194-10198 (2000).

[26] G.M. Song, Y.T. Pei, W.G. Sloof, S.B. Li, J.T.M. De Hosson, and S. van der Zwaag, Oxidation-induced crack healing in $\mathrm{Ti}_{3} A l C_{2}$ ceramics, Scr. Mater. 58 13-16 (2008).

[27] H.J. Yang, Y.T. Pei, J.C. Rao, J.T.M. De Hosson, S.B. Li, and G.M. Song, High temperature healing of $\mathrm{Ti}_{2} \mathrm{AlC}$ : On the origin of inhomogeneous oxide scale, Scr. Mater. 65 135-138 (2011).

[28] M.W. Barsoum, I. Salama, T. El-Raghy, J. Golczewski, W.D. Porter, H. Wang, H.J. Seifert, and F. Aldinger, Thermal and electrical properties of $\mathrm{Nb}_{2} \mathrm{AlC}$, $(\mathrm{Ti}, \mathrm{Nb})_{2} \mathrm{AlC}$ and $\mathrm{Ti}_{2} \mathrm{AlC}$, Metall. Mater. Trans. A 33 2775-2779 (2002).

[29] J.C. Schuster, V.H. Nowotny, and C. Vaccaro, The ternary systems: $C r-A l-C, V-A l-C$, and $\mathrm{Ti}-\mathrm{Al}-\mathrm{C}$ and the behavior of H-phases $\left(\mathrm{M}_{2} \mathrm{AlC}\right)$, J. Solid State Chem. 32 213-219 (1980).

[30] B. Manoun, S.K. Saxena, G. Hug, A. Ganguly, E.N. Hoffman, and M.W. Barsoum, Synthesis and compressibility of $\mathrm{Ti}_{3}\left(A l, \mathrm{Sn}_{0.2}\right) \mathrm{C}_{2}$ and $\mathrm{Ti}_{3} \mathrm{Al}\left(\mathrm{C}_{0.5}, N_{0.5}\right)_{2}$, J. Appl. Phys. 101113523 (2007).

[31] H. Yang, B. Manoun, R.T. Downs, A. Ganguly, and M.W. Barsoum, Crystal chemistry of layered carbide, $\mathrm{Ti}_{3}\left(\mathrm{Si}_{0.43} \mathrm{Ge}_{0.57}\right) \mathrm{C}_{2}$, J. Phys. Chem. Solids 67 2512-2516 (2006).

[32] M.W. Barsoum, M. Ali, and T. El-Raghy, Processing and characterization of $\mathrm{Ti}_{2} \mathrm{AlC}$, $\mathrm{Ti}_{2} A l N$, and $\mathrm{Ti}_{2} A l C_{0.5} N_{0.5}$, Metall. Mater. Trans. A 31(7) 1857-1865 (2000).

[33] F.L. Meng, Y.C. Zhou, and J. Wang, Strengthening of $T i_{2} A l C$ by substituting Ti with $V$, Scr. Mater. 53 1369-1372 (2005).

[34] Y. Zhou, F. Meng, and J. Zhang, New MAX-phase compounds in the V-Cr-Al-C system, J. Am. Ceram. Soc. 91(4) 1357-1360 (2008). 
[35] J. Rosen, P.O.A. Persson, M. Ionescu, A. Kondyurin, D.R. McKenzie, and M.M.M. Bilek, Oxygen incorporation in Ti $i_{2} A l C$ thin films, Appl. Phys. Lett. 92 064102 (2008).

[36] T. Liao, J. Wang, M. Li, and Y. Zhou, First-principles study of oxygen incorporation and migration mechanisms in $\mathrm{Ti}_{2} \mathrm{AlC}$, J. Mater. Res. 24(10) 3190-3196 (2009).

[37] M. Dahlqvist and J. Rosen, Defect formation and oxygen incorporation in $\mathrm{Ti}_{2} \mathrm{AlC}$, $V_{2} A l C$, and $\mathrm{Cr}_{2} \mathrm{AlC}$ from first principles calculations, in manuscript.

[38] P.O.Å. Persson, J. Rosen, D.R. McKenzie, and M.M.M. Bilek, Formation of the MAXphase oxycarbide $\mathrm{Ti}_{2} A l C_{1-x} \mathrm{O}_{x}$ studied via electron energy-loss spectroscopy and firstprinciples calculations, Phys. Rev. B 80092102 (2009).

[39] P.O.Å. Persson, C. Höglund, J. Birch, and L. Hultman, $\mathrm{Ti}_{2} \mathrm{Al}(\mathrm{O}, \mathrm{N})$ formation by solid state reaction between substoichiometric TiN thin films and $\mathrm{Al}_{2} \mathrm{O}_{3}(0001)$ substrates, Thin Solid Films 519 2421-2425 (2010).

[40] J. Emmerlich, D. Music, P. Eklund, O. Wilhelmsson, U. Jansson, J.M. Schneider, H. Högberg, and L. Hultman, Thermal stability of $\mathrm{Ti}_{3} \mathrm{SiC}_{2}$ thin films, Acta Mater. 55 1479-1488 (2007).

[41] M. Dahlqvist, B. Alling, I.A. Abrikosov, and J. Rosen, Phase stability of $\mathrm{Ti}_{2} \mathrm{AlC}$ upon oxygen incorporation: A first principles investigation, Phys. Rev. B 81024111 (2010).

[42] A. Mockute, M. Dahlqvist, L. Hultman, P.O.A. Persson, and J. Rosen, Oxygen incorporation in $\mathrm{Ti}_{2} \mathrm{AlC}$ thin films studied by electron energy loss spectroscopy and ab initio calculations, J. Mater. Sci. 48(10) 3686-3691 (2013).

[43] M. Baben, L. Shang, J. Emmerlich, and J.M. Schneider, Oxygen incorporation in $M_{2} A l C(M=T i, V, C r)$, Acta Mater. (60) 4810-4818 (2012).

[44] M. Dahlqvist, B. Alling, and J. Rosen, Correlation between magnetic state and bulk modulus of $\mathrm{Cr}_{2} \mathrm{AlC}$, J. Appl. Phys. 113216103 (2013).

[45] W. Zhou, L. Liu, and P. Wu, First-principles study of structural, thermodynamic, elastic, and magnetic properties of $\mathrm{Cr}_{2} \mathrm{GeC}$ under pressure and temperature, J. Appl. Phys. 106033501 (2009).

[46] M. Mattesini and M. Magnuson, Electronic correlation effects in the $\mathrm{Cr}_{2} \mathrm{GeC} \mathrm{M}_{n+1} A X_{n}$ phase, J. Phys.: Condens. Matter. 25 (2013).

[47] A. Petruhins, A.S. Ingason, M. Dahlqvist, A. Mockute, M. Junaid, J. Birch, J. Lu, L. Hultman, P.O.Å. Persson, and J. Rosen, Phase stability of $\mathrm{Cr}_{n+1} \mathrm{GaC}_{n}$ MAX phases from first principles and $\mathrm{Cr}_{2} \mathrm{GaC}$ thin-film synthesis using magnetron sputtering from elemental targets, Phys. Status Solidi RRL 7(11) 971-974 (2013).

[48] Z. Liu, T. Waki, Y. Tabata, K. Yuge, and H. Nakamura, Magnetic ground state of the $M_{n+1} A X_{n}$-phase nitride $\mathrm{Cr}_{2} G a N$, Phys. Rev. B 88134401 (2013). 
[49] P. Finkel, J.D. Hettinger, S.E. Lofland, M.W. Barsoum, and T. El-Raghy, Magnetotransport properties of the ternary carbide $\mathrm{Ti}_{3} \mathrm{SiC}_{2}$ : Hall effect, magnetoresistance, and magnetic susceptibility, Phys. Rev. B 65035113 (2001).

[50] P. Finkel, M.W. Barsoum, J.D. Hettinger, S.E. Lofland, and H.I. Yoo, Lowtemperature transport properties of nanolaminates $T_{3} A l C_{2}$ and $T i_{4} A l N_{3}$, Phys. Rev. B 67235108 (2003).

[51] C.C. Li, B.S. Wang, S. Lin, J.C. Lin, P. Tong, W.J. Lu, and Y.P. Sun, Magnetic/structural phase diagram and enhanced giant magnetoresistance in Zndoped antiperovskite compound $\mathrm{Ga}_{1-x} \mathrm{Zn}_{x} \mathrm{CMn}_{3}$, J. Magn. Magn. Mater. $3232233-$ 2237 (2011).

[52] B.S. Wang, C.C. Li, S. Lin, J.C. Lin, L.J. Li, P. Tong, W.J. Lu, X.B. Zhu, Z.R. Yang, W.H. Song, J.M. Dai, and Y.P. Sun, Magnetic properties and room-temperature magnetocaloric effect in the doped antiperovskite compounds $\mathrm{Ga}_{1-x} \mathrm{Al}_{x} \mathrm{CMn}_{3}$ $(0<=x<=0.15)$, J. Magn. Magn. Mater. 323 2017-2022 (2011).

[53] M.M.M. Bilek and W.I. Milne, Electronic properties of filtered cathodic vacuum arc (FCVA) deposited silicon thin films, Electron. Lett. 32(21) 2016-2018 (1996).

[54] F. Richter, G. Krannich, J. Hahn, R. Pintaske, M. Friedrich, S. Schmidbauer, and D.R.T. Zahn, Utilization of cathodic arc evaporation for the deposition of boron nitride thin films, Surf. Coat. Tech. 90 178-183 (1997).

[55] T.W.H. Oates, J. Pigott, D.R. McKenzie, and M.M.M. Bilek, A high-current pulsed cathodic vacuum arc plasma source, Rev. Sci. Instrum. 74(11) 4750-4754 (2003).

[56] M.C. Guenette, M.D. Tucker, M. Ionescu, M.M.M. Bilek, and D.R. McKenzie, Cathodic arc co-deposition of highly oriented hexagonal Ti and $\mathrm{Ti}_{2} \mathrm{AlC} \mathrm{MAX}$ phase thin films, Thin Solid Films 519 766-769 (2010).

[57] P. Eklund, M. Beckers, J. Frodelius, H. Högberg, and L. Hultman, Magnetron sputtering of $\mathrm{Ti}_{3} \mathrm{SiC}_{2}$ thin films from a compound target, J. Vac. Sci. Technol. 25(5) 1381-1388 (2007).

[58] S.-J.L. Kang, Sintering: Densification, grain growth and microstructure 2005: Elsevier.

[59] B.J. Kooi, R.J. Poppen, N.J.M. Carvalho, J.T.M. De Hosson, and M.W. Barsoum, $\mathrm{Ti}_{3} \mathrm{SiC}_{2}$ : A damage tolerant ceramic studied with nanoindentations and transmission electron microscopy, Acta Mater. 51 2859-2872 (2003).

[60] J. Emmerlich, H. Högberg, S. Sasvari, P.O.A. Persson, L. Hultman, J.-P. Palmquist, U. Jansson, J.M. Molina-Aldareguia, and Z. Czigany, Growth of $\mathrm{Ti}_{3} \mathrm{SiC}_{2}$ thin films by elemental target magnetron sputtering, J. Appl. Phys. 96(9) 4817-4826 (2004).

[61] W. Olek and J. Bonarski, Texture function application for wood ultrastructure description. Part 2: Application, Wood Sci. Technol. 40(4) 336-349 (2005). 
[62] J.J. Nickl, K.K. Schweitzer, and P. Luxenberg, Gasphasenabscheidung im system TiSi-C, J. Less Common Met. 26 335-353 (1971).

[63] R. Mertens, Z. Sun, D. Music, and J.M. Schneider, Effect of the composition on the structure of $\mathrm{Cr}-\mathrm{Al}-\mathrm{C}$ investigated by combinatorial thin film synthesis and ab initio calculations, Adv. Eng. Mater. 6(11) 903-907 (2004).

[64] C. Walter, D.P. Sigumonrong, T. El-Raghy, and J.M. Schneider, Towards large area deposition of $\mathrm{Cr}_{2}$ AlC on steel, Thin Solid Films 515 389-393 (2006).

[65] T. Joelsson, A. Hörling, J. Birch, and L. Hultman, Single-crystal Ti ${ }_{2} A l N$ thin films, Appl. Phys. Lett. 86111913 (2005).

[66] C. Lange, M.W. Barsoum, and P. Schaaf, Towards the synthesis of MAX-phase functional coatings by pulsed laser deposition, Appl. Surf. Sci. 254 1232-1235 (2007).

[67] C. Lange, M. Hopfeld, M. Wilke, J. Schawohl, T. Kups, M.W. Barsoum, and P. Schaaf, Pulsed laser deposition from a pre-synthesized $C r_{2} A l C$ MAX phase target with and without ion-beam assistance, Phys. Status Solidi A 209(3) 545-552 (2012).

[68] T.F. Zhang, Q.M. Wang, J. Lee, P. Ke, R. Nowak, and K.H. Kim, Nanocrystalline thin films synthesized from a $\mathrm{Ti}_{2} \mathrm{AlN}$ compound target by high power impulse magnetron sputtering technique, Surf. Coat. Tech. 212 199-206 (2012).

[69] Y. Jiang, S. Mraz, and J.M. Schneider, Growth of V-Al-C thin films by direct current and high power impulse magnetron sputtering from a powder metallurgical composite target, Thin Solid Films 583 1-6 (2013).

[70] J. Rosen, L. Ryves, P.O.Å. Persson, and M.M.M. Bilek, Deposition of epitaxial Ti ${ }_{2} A l C$ thin films by pulsed cathodic arc, J. Appl. Phys. 101056101 (2007).

[71] M.D. Tucker, P.O.A. Persson, M.C. Guenette, J. Rosen, M.M.M. Bilek, and D.R. McKenzie, Substrate orientation effects on the nucleation and growth of the $M_{n+1} A X_{n}$ phase $T i_{2} A l C$, J. Appl. Phys. 109014903 (2011).

[72] A. Flink, J. Sjölen, and L. Hultman, unpublished results.

[73] C. Höglund, M. Beckers, N. Schell, J. Borany, J. Birch, and L. Hultman, Topotaxial growth of $\mathrm{Ti}_{2} \mathrm{AlN}$ by solid state reaction in AlN/Ti(0001) multilayer thin films, Appl. Phys. Lett. 90174106 (2007).

[74] B. Veisz and B. Pecz, Polarity dependent Al-Ti contacts to 6H-SiC, Appl. Surf. Sci. 233 360-365 (2004).

[75] P.O.Å. Persson, J. Rosen, D.R. McKenzie, M.M.M. Bilek, and C. Höglund, A solid phase reaction between $\mathrm{TiC}_{x}$ thin films and $\mathrm{Al}_{2} \mathrm{O}_{3}$ substrates, J. Appl. Phys. 103 066102 (2008). 
[76] J. Zhang, L. Wang, W. Jiang, and L. Chen, Fabrication of high purity $\mathrm{Ti}_{3} \mathrm{SiC}_{2}$ from Ti/Si/C with the aids of Al by spark plasma sintering, J. Alloy Compd. 437 203-207 (2007).

[77] S. Konoplyuk, T. Abe, T. Uchimoto, and T. Takagi, $\mathrm{Ti}_{3} \mathrm{SiC}_{2} / \mathrm{TiC}$ composites prepared by PDS, J. Mater. Sci. 40 3409-3413 (2005).

[78] Z. Ge, K. Chen, J. Guo, H. Zhou, and J.M.F. Ferreira, Combustion synthesis of ternary carbide $\mathrm{Ti}_{3} \mathrm{AlC}_{2}$ in Ti-Al-C system, J. Eur. Ceram. Soc. 23 567-574 (2003).

[79] C.L. Yeh and Y.G. Shen, Effects of SiC addition on formation of $\mathrm{Ti}_{3} \mathrm{SiC}_{2}$ by selfpropagating high-temperature synthesis, J. Alloy Compd. 461 654-660 (2008).

[80] L. Yongming, P. Wei, L. Shuqin, C. Jian, W. Ruigang, and L. Jianqiang, Synthesis of high-purity $\mathrm{Ti}_{3} \mathrm{SiC}_{2}$ polycrystals by hot-pressing of the elemental powders, Mater. Lett. 52 245-247 (2002).

[81] S. Amini, A. Zhou, S. Gupta, A. DeVillier, P. Finkel, and M.W. Barsoum, Synthesis and elastic and mechanical properties of $\mathrm{Cr}_{2} \mathrm{GeC}$, J. Mater. Res. 23 2157-2165 (2008).

[82] M.W. Barsoum, MAX phases: Properties of machinable ternary carbides and nitrides 2013: Wiley-VCH.

[83] J. Etzkorn, M. Ade, D. Kotzott, M. Kleczek, and H. Hillebrecht, $T i_{2} G a C, T i_{4} G a C_{3}$ and $\mathrm{Cr}_{2} \mathrm{GaC}$ - Synthesis, crystal growth and structure analysis of Ga-containing MAXphases $M_{n+1} G a C_{n}$ with $M=T i, C r$ and $n=1$, 3, J. Solid State Chem. 182(5) 995-1002 (2009).

[84] M. Dahlqvist, A. Thore, A.S. Ingason, A. Petruhins, A. Mockute, R. Meshkian, M. Sahlberg, F. Magnus, B. Hjorvarsson, P.O.A. Persson, B. Alling, I.A. Abrikosov, and J. Rosen, Complex magnetism in nanolaminated $M n_{2} G a C$, in manuscript. 



\section{Included Papers}

The articles associated with this thesis have been removed for copyright reasons. For more details about these see:

http://urn.kb.se/resolve?urn=urn:nbn:se:liu:diva-104829 